\title{
LOTUS Inhibits Neuronal Apoptosis and Promotes Tract Regeneration in Contusive Spinal Cord Injury Model Mice
}

\author{
DShuhei Ito, ${ }^{1,2}$ Narihito Nagoshi, ${ }^{1,2}$ Osahiko Tsuji, ${ }^{2}$ Shinsuke Shibata, ${ }^{1}$ Munehisa Shinozaki, ${ }^{1}$ Soya \\ Kawabata, ${ }^{1,2}$ - Kota Kojima, ${ }^{1,2}$ Kaori Yasutake, ${ }^{1}$ Tomoko Hirokawa, ${ }^{3}$ - Morio Matsumoto, ${ }^{2}$ (๑) Kohtaro \\ Takei, ${ }^{3}$ Masaya Nakamura, ${ }^{2}$ and ${ }^{\circ}$ Hideyuki Okano ${ }^{1}$
}

https://doi.org/10.1523/ENEURO.0303-18.2018

${ }^{1}$ Department of Physiology, Keio University School of Medicine, Tokyo 160-8582, Japan, ${ }^{2}$ Department of Orthopaedic Surgery, Keio University School of Medicine, Tokyo 160-8582, Japan, and ${ }^{3}$ Molecular Medical Bioscience Laboratory, Yokohama City University Graduate School of Medical Life Science, Yokohama 230-0045, Japan

\begin{abstract}
Nogo receptor-1 (NgR1) signaling is involved in the limitation of axonal regeneration following spinal cord injury (SCl) through collapsing the growth cone and inhibiting neurite outgrowth. Lateral olfactory tract usher substance (LOTUS), a NgR antagonist, suppresses these pathological conditions. A previous report demonstrated the positive effects of LOTUS expression on motor function through raphespinal tract regeneration using panneuronally LOTUS-overexpressing transgenic mice. However, this report used a hemi-section model, which does not represent the majority of clinical $\mathrm{SCl}$ cases, and lacked a detailed histological analysis of other descending tracts. To determine the true therapeutic effects of LOTUS, we used a more clinically relevant contusive $\mathrm{SCI}$ model in female transgenic mice. Definitive tracing analyses revealed that LOTUS promoted the extensive regeneration of the reticulospinal tract across the lesion site and suppressed axonal dieback of corticospinal tract (CST). A significant increase in raphespinal tract fibers was seen from the subacute to the chronic phase after the injury, strongly suggesting that LOTUS promoted translesional elongation of this tract. Furthermore, histological analyses revealed that LOTUS had a neuroprotective effect on the injured spinal cord through suppressing cellular apoptosis during the acute phase. These neuroprotective and regenerative effects contributed to significant motor functional recovery and restoration of the motor evoked potential (MEP). Therefore, LOTUS application could prove beneficial in the treatment of $\mathrm{SCl}$ by promoting axonal regeneration of some descending fibers, reducing axonal dieback of CST fibers and encouraging motor function recovery.
\end{abstract}

Key words: axonal regeneration; LOTUS; neuronal protection; Nogo receptor; spinal cord injury; transgenic mice

\section{Significance Statement}

Axonal regeneration following spinal cord injury $(\mathrm{SCl})$ is extremely limited due to Nogo receptor (NgR) signaling, which inhibits neurite outgrowth and collapses growth cones. Lateral olfactory tract usher substance (LOTUS), a NgR antagonist, suppresses this inhibition by NgR. Here, we evaluated the therapeutic effects of LOTUS using a clinically relevant contusive SCI model. Our data revealed that LOTUS promoted extensive translesional regeneration of the reticulospinal and raphespinal tracts and rostral regeneration of the corticospinal tract. Furthermore, LOTUS suppressed cellular apoptosis during the acute phase, and these neuroprotective and regenerative effects contributed to significant recovery of motor function and nerve conduction. Therefore, this study suggested that LOTUS could aid the treatment of SCI by promoting axonal regeneration and motor function recovery. 


\section{Introduction}

Natural recovery following spinal cord injury (SCl) is extremely limited in mammalian adults (Schwab, 2010) due to the inhibition of axonal regeneration controlled by Nogo receptor-1 (NgR1) signaling (Fournier et al., 2001). In the injured spinal cord, ligands of NgR1, such as Nogo (GrandPré et al., 2000), myelin-associated glycoprotein (MAG; McKerracher et al., 1994), oligodendrocyte myelin glycoprotein (OMgp; Wang et al., 2002b), B lymphocyte stimulator (BLyS; Zhang et al., 2009), and chondroitin sulfate proteoglycans (CSPGs; Silver and Miller, 2004), bind to NgR1, which interacts with coreceptor p75 (Wang et al., 2002a). Downstream, Ras homolog gene family, member A (Rho-A) and Rho-associated kinase (ROCK) are activated, causing growth cone collapse, thereby inhibiting neuronal regeneration (Domeniconi et al., 2002; Dickendesher et al., 2012).

Since NgR1 plays an important role in controlling neuronal outgrowth, the important role of its signal cascade in the treatment of $\mathrm{SCl}$ has been recognized. Previous reports have mainly focused on axonal regeneration of the corticospinal tract (CST; Lemon, 2008). However, the results from several studies using Nogo-deficient mice to evaluate its impact on CST fibers and motor function have been inconsistent (Kim et al., 2003; Simonen et al., 2003; Zheng et al., 2003). Mice lacking MAG or OMgp also failed to regenerate the CST following SCI (Bartsch et al., 1995; $\mathrm{Ji}$ et al., 2008). Kim et al. (2004) demonstrated locomotor recovery after $\mathrm{SCl}$ by inhibiting a common receptor of all ligands using NgR1-lacking mice. Interestingly, this animal model exhibited regeneration of the raphespinal tract, which plays an important role in the formation of connections with the motor neural circuit after SCl (Liang et al., 2015). Therefore, by blocking the downstream Rho-ROCK

Received August 6, 2018; accepted October 5, 2018; First published October 22, 2018.

H.O. serves as a paid scientific advisor to SanBio Co. Ltd and K Phama Inc. All other authors declare no competing financial interests.

Author contributions: S.I., S.K., M.N., and H.O. designed research; S.I., N.N., O.T., S.S., M.S., S.K., K.K, K.Y., T.H., K.T., and M.M. performed research; K.T. contributed unpublished reagents/analytic tools; S.I. analyzed data; S.I., N.N., M.N., and H.O. wrote the paper.

This work was supported by the Japan Agency for Medical Research and Development (AMED) Grant 15bm0204001h0003 (to H.O. and M.N.) and in part by The General Insurance Association of Japan medical research grant on traffic accidents 16-1-20.

Acknowledgements: We thank the assistance of F. Renault-Mihara, Y. Nishiyama, K. Sugai, M. Ozaki, K. Matsubayashi, T. lida, T. Okubo, Y. Hoshino, Y. Tanimoto, R. Shibata, Y. Kamata, and K. Kajikawa, who are all members of the spinal cord research team at the Department of Orthopaedic Surgery and Physiology, Keio University School of Medicine, Tokyo, Japan. We also thank R. Kashiwagi, T. Harada, and M. Akizawa for their assistance with the experiments and animal care.

Correspondence should be addressed to either of the following: Masaya Nakamura, Department of Orthopaedic Surgery, Keio University School of Medicine, Tokyo 160-8582, Japan, E-mail: masa@keio.jp; or Hideyuki Okano, Department of Physiology, Keio University School of Medicine, Tokyo 1608582, Japan, E-mail: hidokano@a2.keio.jp.

https://doi.org/10.1523/ENEURO.0303-18.2018

Copyright @ 2018 Ito et al.

This is an open-access article distributed under the terms of the Creative Commons Attribution 4.0 International license, which permits unrestricted use, distribution and reproduction in any medium provided that the original work is properly attributed. cascade, the $\mathrm{NgR} 1$ antagonist may enhance tract regeneration following SCl.

Recently, cartilage acidic protein-1B (Crtac1B) has been identified as a lateral olfactory tract usher substance (LOTUS), which is both a membrane and secreted protein that functions as an endogenous antagonist against NgR1 (Sato et al., 2011; Kurihara et al., 2012). LOTUS binds to $\mathrm{NgR} 1$ and inhibits all ligand proteins, resulting in decreased growth cone collapse and neurite outgrowth inhibition (Kurihara et al., 2014, 2017; Kawakami et al., 2018). In focal brain ischemia model mice, LOTUS overexpression on the contralateral side of the injury accelerated axonal sprouting that crossed the midline to the ipsilateral side, enhancing the neuronal plasticity of motor pathways (Takase et al., 2017). LOTUS overexpression was recently demonstrated to enhance the regeneration of raphespinal tract fibers across the lesion, thereby contributing to motor functional recovery (Hirokawa et al., 2017).

In the above paper, the authors used dorsal hemisection to model $\mathrm{SCl}$ and observed tract fiber regeneration. However, transection injury is rarely observed in the clinical setting. In fact, a previous study advocated that contusive injury is more clinically relevant than complete or partial transection (Kwon et al., 2011). Therefore, the efficacy of LOTUS in preclinical studies should be evaluated using contusive injury models. Additionally, the previous study evaluated only raphespinal tracts and did not examine CST and reticulospinal tracts. Particularly, the reticulospinal tract is strongly involved in the neural networks that coordinate rhythmic stepping movements (Fink and Cafferty, 2016). Finally, although the aforementioned study illustrated an increase in 5-hydroxytryptamine (5-HT)-positive raphespinal tract axons in the chronic stage, whether this phenomenon was a result of axonal preservation or regeneration after $\mathrm{SCl}$ remains unclear. Antagonistic activity against NgR1 or Rho-A can suppress apoptosis following CNS injury (Dubreuil et al., 2003; Wang et al., 2008), implying that LOTUS, a NgR1 antagonist, could also exert its neuroprotective effect during the acute inflammatory phase following SCl.

In the present study, we evaluated the effect of LOTUS on spinal contusive injury using transgenic mice overexpressing LOTUS by specifically focusing on axonal regeneration in various tract fibers, such as the corticospinal, reticulospinal and raphespinal tracts, using tracing and various histologic methods. Moreover, we investigated the neuroprotective effect of LOTUS during the acute stage of SCl. This study is the first to demonstrate the beneficial effect of LOTUS in a clinically relevant traumatic $\mathrm{SCl}$ animal model.

\section{Materials and Methods}

\section{Animals}

LOTUS-overexpressing (LOTUS-Tg) mice were generated using the mouse synapsin-1 promoter, which selectively expresses neuron-specific LOTUS as previously described (Hirokawa et al., 2017). C57BL/6J mice were purchased from CLEA Japan, Inc. We used LOTUS-Tg and C57BL/6J mice (eight-week-old, female, 18-22 g) in 
this study. All experiments were approved by the ethics committee of Keio University and were in accordance with the Guide for the Care and Use of Laboratory Animals (National Institutes of Health, Bethesda, MD).

\section{$\mathrm{SCI}$ model}

All mice were anesthetized by intraperitoneal injections of ketamine $(60 \mathrm{mg} / \mathrm{kg})$ and xylazine $(10 \mathrm{mg} / \mathrm{kg})$. The laminal arch of the vertebrae at the tenth thoracic level was removed, and the exposed dura mater was subjected to a 70-kdyn contusive SCI using a commercially available $\mathrm{SCl}$ device (IH Impactor, Precision Systems and Instrumentation) as previously described (Scheff et al., 2003). After $\mathrm{SCl}, 12.5 \mathrm{mg} / \mathrm{kg}$ ampicillin was administered intramuscularly.

\section{Western blot analysis}

For intact mice, 4-mm-long samples of the spinal cord centered at the tenth thoracic level were used for analysis. Tissue samples were homogenized in lysis buffer, and $10-\mu \mathrm{g}$ protein was electrophoretically separated on 4-20\% gradient polyacrylamide gels and transferred onto polyvinylidene difluoride (PVDF) membranes. Membranes were blocked with $5 \%$ skim milk in Tris-buffered saline, $0.1 \%$ Tween 20 (TBST) for $1 \mathrm{~h}$ at room temperature (RT) and then incubated overnight at $4^{\circ} \mathrm{C}$ with an affinitypurified monoclonal mouse antibody against LOTUS (ITM). After the membranes were washed with TBST, they were incubated with horseradish peroxidase-conjugated secondary antibody for $1 \mathrm{~h}$ at RT. The bands were visualized using an enhanced chemiluminescence reagent (GE Healthcare) and an ImageQuant LAS 4000 instrument (GE Healthcare). The quantification of each band was performed using the National Institutes of Health image analyzer.

\section{Behavioral analyses}

The hindlimb motor function of each mouse was evaluated weekly using the Basso mouse scale (BMS) up to $42 \mathrm{~d}$ after injury (Basso et al., 2006). Two persons blinded to the mouse group performed the behavioral analyses. At $42 \mathrm{~d}$ after injury, motor function was also assessed on a rotating rod apparatus (KDS310; Muromachi-Kikai Co., Ltd.) by measuring the amount of time that mice could remain on the rod while it rotated at 10 rotations per minute (rpm). A treadmill gait analysis was performed using the DigiGait System (Mouse Specifics). The stride lengths and stance angles of the hindlimbs were measured on a treadmill at a speed of $6 \mathrm{~cm} / \mathrm{s}$, and phase dispersion was analyzed in the DigiGait analyses to provide an indication of limb coordination.

\section{Electrophysiology}

Electrophysiological experiments were performed using a Neuropack S1 MEB $_{9402}$ signal processor (Nihon Kohden; http://www.nihonkohden.co.jp) at $56 \mathrm{~d}$ postinjury as previously described (Nori et al., 2011). Mice were anesthetized by intraperitoneal injections of ketamine (60 $\mathrm{mg} / \mathrm{kg}$ ) and xylazine $(10 \mathrm{mg} / \mathrm{kg})$, and a C1 laminectomy was performed ( $n=10$, each group). The occipitocervical area of the spinal cord was stimulated, and the signal in the hindlimb was detected by needle electrodes. The active electrode was placed in the quadriceps muscle belly, the reference electrode was placed near the distal quadriceps tendon of the muscle, and the ground electrode was placed in the tail. Stimulation with an intensity of $0.8 \mathrm{~mA}$, duration of $0.2 \mathrm{~ms}$, and interstimulus interval of $1 \mathrm{~Hz}$ was used. The latency was measured as the length of time from the stimulation to the onset of the first response wave. The amplitude was measured from the initiation point of the first response wave to its highest point.

\section{Immunohistochemistry (IHC)}

Anesthetized mice were transcardially perfused with saline solution, followed by $4 \%$ paraformaldehyde PBS 56 $\mathrm{d}$ after injury. Spinal cords were dissected and postfixed in $4 \%$ paraformaldehyde for $2 \mathrm{~h}$ at RT. Fixed spinal cords were soaked in $10 \%$ sucrose in $0.1 \mathrm{M}$ PBS overnight at $4^{\circ} \mathrm{C}$, followed by $30 \%$ sucrose, embedding in Optimal Cutting Temperature compound (Sakura Finetechnical Co., Ltd.), and freezing as previously described (Nishimura et al., 2013). Samples were sectioned in the sagittal plane at a thickness of $14 \mu \mathrm{m}$ or the axial plane at a thickness of 20 $\mu \mathrm{m}$ on a cryostat (Leica CM3050 S, Leica Microsystems). Histologic analyses of the sections were performed by hematoxylin-eosin (HE) staining, Luxol fast blue (LFB) staining and IHC. Tissue sections were stained with the following primary antibodies for IHC: anti-human influenza hemagglutinin [HA; rabbit immunoglobulin G (IgG), 1:500; CosmoBio], anti-glial fibrillary acidic protein (GFAP; rabbit IgG, 1:500; Dako, Z0334), anti-neurofilament 200 kDa (NF-H; mouse lgG, 1:500; Millipore, MAB5262), anti-5-HT (goat IgG, 1:500; Immunostar, Inc., 20079), antiphosphorylated growth-associated protein 43 (p-GAP43; mouse IgG, 1:1000; Wako, 18-10H-9H), anti-neuronal nuclear protein (NeuN; mouse IgG, 1:500; Millipore Bioscience Research Reagents, MAB377), and anti-cleaved caspase-3 (rabbit IgG, 1:500; Cell Signaling, 9661). Then, the sections were incubated with Alexa Fluor-conjugated secondary antibodies (1:1000). For IHC with anti-pGAP43, a biotinylated secondary antibody (Jackson ImmunoResearch Laboratories Inc.) was used after the tissue was exposed to $1.0 \% \mathrm{H}_{2} \mathrm{O}_{2}$ for $30 \mathrm{~min}$ at $\mathrm{RT}$ to inactivate endogenous peroxidases. Signals were enhanced with a Vectastain ABC kit (Vector Laboratories, Inc.). Nuclei were stained with Hoechst $33258(10 \mu \mathrm{g} / \mathrm{ml}$, Sigma-Aldrich). All images were obtained using a fluorescence microscope (BZ-X710; Keyence Co.) and a confocal laser scanning microscope (LSM 700, Carl Zeiss).

\section{Terminal deoxynucleotidyl transferase-mediated dUTP nick end labeling (TUNEL) staining}

Apoptotic cells were detected using the TUNEL method. TUNEL staining was performed using an In Situ Cell Death Detection kit, Fluorescein (Roche). At $7 \mathrm{~d}$ postinjury, axial sections were costained with TUNEL and Hoechst 33258, and only TUNEL-positive cells that correlated with Hoechst-positive nuclei were counted. The percentage of apoptotic cells was quantified by counting the numbers of TUNEL-positive cells at the margin of the 
lesion in epicenter axial sections under a $400 \times$ objective ( $n=5$, each group).

\section{Anterograde labeling of the CST}

At $42 \mathrm{~d}$ postinjury, mice in both groups were injected with biotinylated dextran amine (BDA; MW 10,000; $10 \%$ in DW, Invitrogen) to trace the descending CST fibers ( $n=5$, each group). BDA was injected into the right primary motor cortex at the following four sites: 0.5 and $1.5 \mathrm{~mm}$ posterior from bregma and 0.5 and $1.5 \mathrm{~mm}$ lateral from bregma at a depth of $0.7 \mathrm{~mm}$, with $0.3 \mu \mathrm{l}$ injected at each site. Two weeks after injection, the mice were sacrificed, and spinal cord samples were sectioned in the axial plane at a thickness of $20 \mu \mathrm{m}$ on a cryostat. The BDA tracer was visualized by Alexa Fluor 488 conjugated to streptavidin, and histologic analyses were performed.

\section{Retrograde labeling of the reticulospinal tract}

At $42 \mathrm{~d}$ postinjury, mice in both groups were injected with Fluoro-Gold (FG; 4\%; Fluorochrome, Inc) to retrogradely trace reticulospinal tract fibers $(n=5$, each group). FG was injected into the lumbar enlargement of the spinal cord at two sites, $0.5 \mathrm{~mm}$ on either side of the center with $0.5 \mu \mathrm{l}$ injected at each site. One week later, the mice were sacrificed, and histologic analyses were performed.

\section{Quantitative analysis}

The spinal cord area was quantified using HE staining of axial sections at the lesion epicenter and 0.5 and $1.0 \mathrm{~mm}$ rostral and caudal to the epicenter under a $10 \times$ objective ( $n=5$, each group). For the evaluation of the myelinated areas, the LFB-positive areas of axial sections were measured ( $n=5$, each group). To evaluate the lesion area, we measured the GFAP-negative area at the lesion epicenter in midsagittal sections under a $10 \times$ objective $(n=5$, each group). The NF-H- and 5-HT-positive areas in whole axial sections of the lesion epicenter and 2 and $4 \mathrm{~mm}$ rostral and caudal to the epicenter were quantified under a $10 \times$ objective ( $n=5$, each group). Quantitative analysis of the p-GAP43-positive area was performed using the immunoreactive area of the spinal white matter in axial sections $4 \mathrm{~mm}$ caudal to the epicenter under a $20 \times$ objective $(n=$ 5 , each group). CST fibers were evaluated by measuring the BDA-positive area of the dorsal column and ipsilateral and contralateral gray matter in the axial sections every $0.5 \mathrm{~mm}$ from $5.0 \mathrm{~mm}$ rostral to $2.0 \mathrm{~mm}$ caudal to the epicenter under a $20 \times$ objective ( $n=5$, each group). For the obtained images, the threshold value for signal detection was set, and the total number of pixels above a certain intensity was measured as the BDA-positive area (Steward et al., 2008). The axon index of the CST was calculated as a ratio to the dCST area $5.0 \mathrm{~mm}$ rostral to the epicenter. FG-labeled reticulospinal tract neurons within the reticular formation of the brainstem were quantified in each animal from every three slices of axial sections under a $20 \times$ objective ( $n=5$, each group). For analysis of apoptotic cells, cleaved caspase-3-positive nuclei within the automatically captured images of the marginal area of the lesion were counted in each animal from every five images in the axial sections of the epicen- ter under a $40 \times$ objective. These counts were expressed as a percentage of the total nuclei ( $n=3$, each group). All images were quantified using ImageJ (https://imagej.nih.gov/ij/).

\section{Experimental design and statistical analysis}

All data are presented as the mean \pm SEM. Unpaired two-tailed Student's $t$ test was used for single comparisons between the control and LOTUS groups. Repeatedmeasures two-way ANOVA followed by the TukeyKramer test was used for BMS scores. Two-way ANOVA followed by the Bonferroni multiple comparisons test was used for the remainder of the analyses. Differences were considered significant at $p<0.05$ or $p<0.01$.

\section{Results}

\section{Characterization of LOTUS overexpression in LOTUS-transgenic mice}

We used transgenic mice (LOTUS-Tg mice) with heterozygous LOTUS overexpression under the mouse synapsin-1 promoter with a HA tag (Hirokawa et al., 2017). Western blotting of the intact thoracic spinal cord showed a band of overexpressed LOTUS above the 75-kDa band for endogenous LOTUS in LOTUS-Tg mice (Fig. 1A). Quantitative analyses revealed that the expression level of LOTUS in LOTUS-Tg mice was nearly twice that in wildtype mice (Fig. $1 B ; p=0.0002$ ). Immunostaining revealed HA-positive cells in the spinal cord of LOTUS-Tg mice but not in that of wild-type mice (Fig. 1C). In LOTUS-Tg mice, HA-positive cells were costained with NeuN, a neuronal marker, but not GFAP, an astrocyte marker (Fig. 1C,D), indicating that overexpressed LOTUS was expressed in neuronal cells. Furthermore, histologic analysis demonstrated that the overexpressed HA-tagged LOTUS was not expressed in ionized calcium-binding adapter molecule 1 (Iba1)-positive microglia cells (Fig. 1E). However, there was no significant difference in the appearance (body weight) or locomotor behaviors assessed by the BMS score, rota-rod test and DigiGait analysis. The baseline BMS score of intact control and LOTUS-Tg mice was nine, and the cutoff value in the rota-rod test was $120 \mathrm{~s}$ ( $n$ $=5$, each group). The stride lengths, stance angles of the hindlimbs and phase dispersions in DigiGait analyses were as follows: preinjury: control versus LOTUS; stride length: $4.36 \pm 0.57$ versus $4.49 \pm 0.62$; stance angle: $14.03 \pm 4.69$ versus $14.72 \pm 8.44$; phase dispersions: FL-HR; $0.0096 \pm 0.018$ versus $0.0034 \pm 0.038$; FR-HL: $0.011 \pm 0.034$ versus $0.0019 \pm 0.026$; FL-FR: $0.48 \pm$ 0.028 versus $0.48 \pm 0.042$; HL-HR: $0.48 \pm 0.05$ versus $0.49 \pm 0.063$; FR-HR: $0.48 \pm 0.041$ versus $0.5 \pm 0.039$; FL-HL: $0.48 \pm 0.034$ versus $0.49 \pm 0.066$; no significant difference, $n=4$, each group. Similarly, neuronal fibers labeled by 5-HT and NF-H between LOTUS-Tg and wildtype mice showed no significant differences (data not shown).

\section{LOTUS suppresses spinal cord atrophy and protects myelinated neuronal fibers against injury}

To evaluate the effects of pan-neuronally overexpressed LOTUS on the injured spinal cord, we analyzed 
A Control LOTUS

LOTUS

GAPDH

$-37 \mathrm{kDa}$

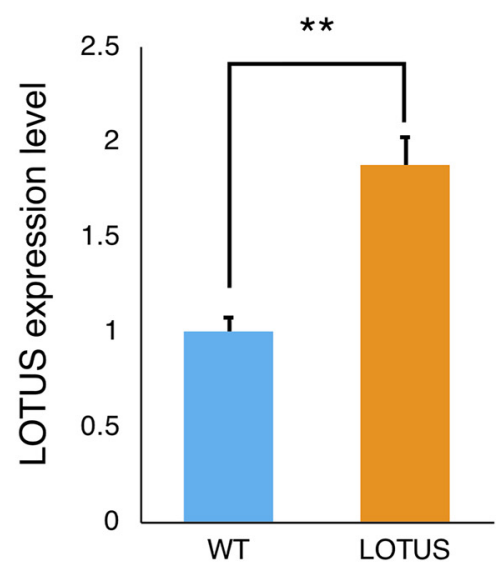

LOTUS
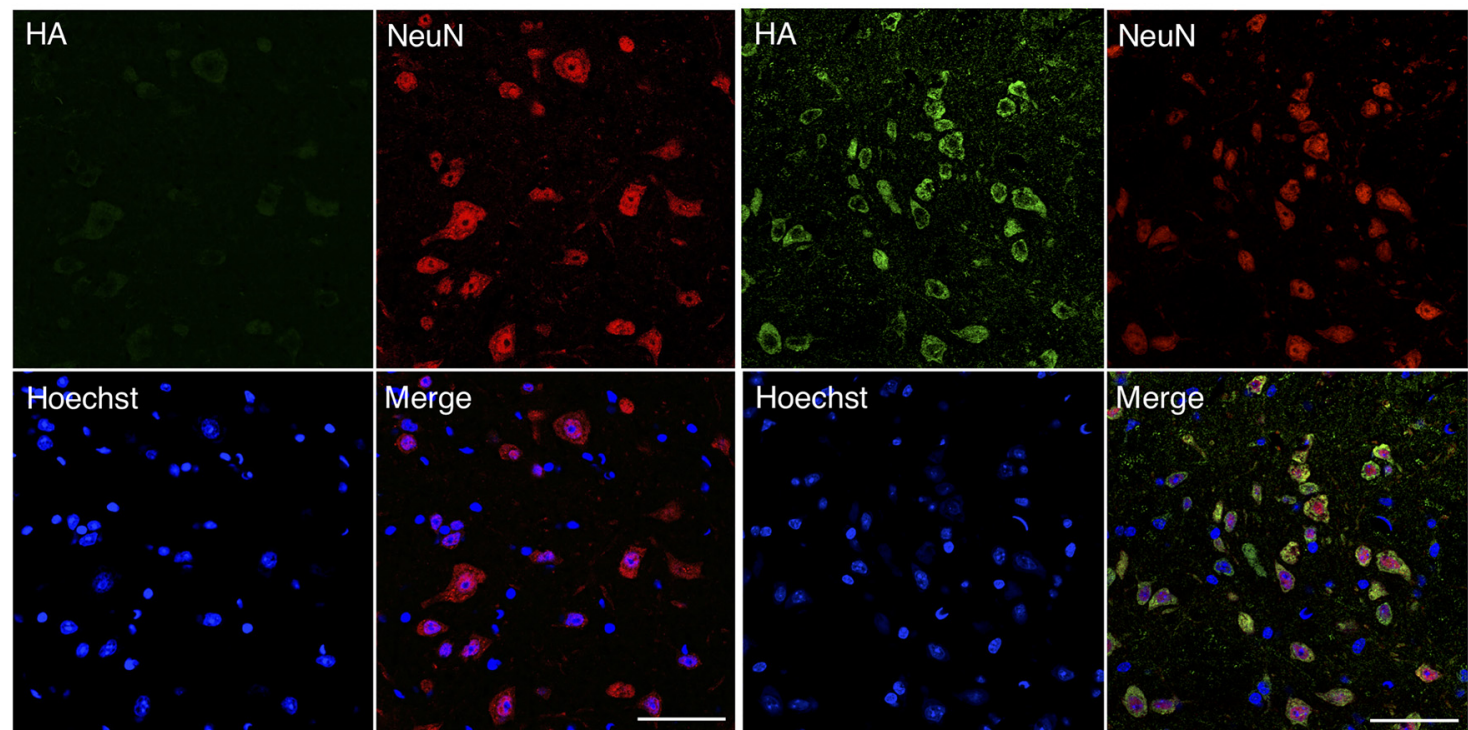

D

LOTUS

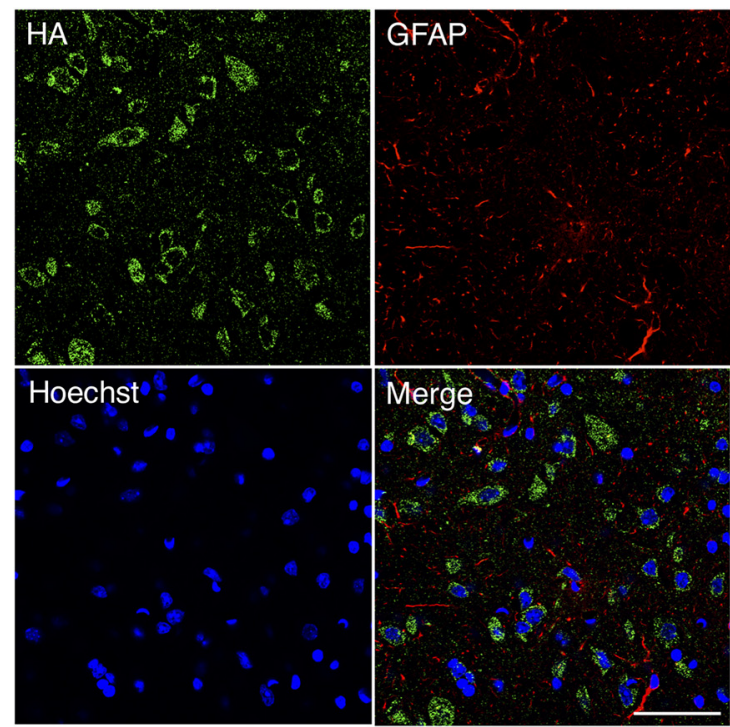

E

\section{LOTUS}

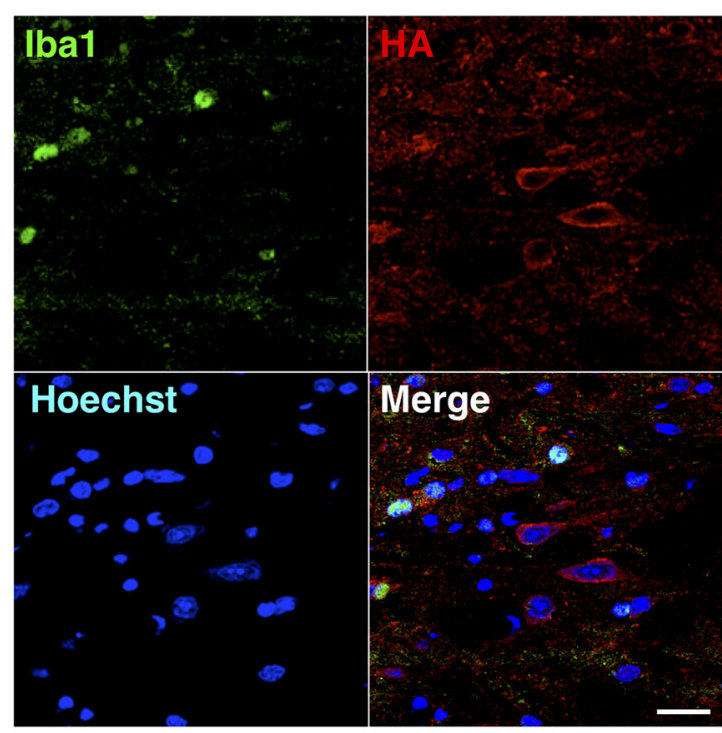

AQ: 3Figure 1. Characterization of LOTUS expression profile in LOTUS-Tg mice. A, Western blot analyses of LOTUS protein 
continued

expression in the thoracic spinal cord. B, Quantitative analyses of the expression level of LOTUS relative to that of GAPDH. $\boldsymbol{C}$, Representative images of overexpressed LOTUS labeled with HA in axial sections at the thoracic level in control and LOTUS-Tg mice. Representative images of HA/NeuN/nuclear triple immunostaining. $\boldsymbol{D}$, Representative images of HA/GFAP/nuclear triple immunostaining in LOTUS-Tg mice. $\boldsymbol{E}$, Representative images of Iba1/HA/nucleus triple immunostaining in the axial section of the LOTUS group at $7 \mathrm{~d}$ postinjury. Values are the mean $\pm \mathrm{SD} ; * p<0.05$. Statistical analysis was performed using unpaired two-tailed Student's $t$ test $(n=5$ each). Scale bars: $50 \mu \mathrm{m}(\boldsymbol{C}, \boldsymbol{D})$ and $20 \mu \mathrm{m}(\boldsymbol{E})$.

axial sections using HE staining at $56 \mathrm{~d}$ postinjury. Quantitative analyses revealed a significantly larger spared volume of the spinal cord area at the injury epicenter and 0.5 $\mathrm{mm}$ caudal to the epicenter in the LOTUS group than in the control group (Fig. $2 A, B$; df $=8,0.5 \mathrm{~mm}$ rostral $p=$ 0.024 ; epicenter $p=0.019 ; 0.5 \mathrm{~mm}$ caudal $p=0.001$ ). To assess the effect of LOTUS on the preservation of myelin, we examined LFB-stained axial sections. The LFBpositive myelinated area in the injured spinal cord was significantly more preserved from $1 \mathrm{~mm}$ rostral to caudal to the epicenter in the LOTUS group than in the control group (Fig. $2 C, D ; 1 \mathrm{~mm}$ rostral $p=0.01 ; 0.5 \mathrm{~mm}$ rostral $p$ $=0.014$; epicenter $p=0.04 ; 0.5 \mathrm{~mm}$ caudal $p=0.002 ; 1$ $\mathrm{mm}$ caudal $p=0.002$ ). To clarify the effects of overexpressed LOTUS on the suppression of atrophy and preservation of myelinated neuronal fibers, we determined the time course changes in the expression level of endogenous and overexpressed LOTUS in the injured spinal cord using Western blotting. Endogenous LOTUS expression gradually decreased in the acute phase after $\mathrm{SCl}$, and a significant decrease was observed at 7 and $14 \mathrm{~d}$ postinjury. For the overexpressed LOTUS, the expression level was not elevated after injury, which suggested that the existing expression level of total LOTUS (endogenous and overexpressed) was sufficient for the neuroprotective effect in LOTUS-Tg mice (Fig. $2 E, F$; day 0 vs day 7 in the control group $p=0.04$; day 0 vs day 7 in the control group $p=0.023$; the control group vs the LOTUS group at every time point $p<0.01$ ). Immunostaining for the astrocytic marker GFAP was performed to measure the size of the lesion area surrounded by reactive astrocytes $56 \mathrm{~d}$ postinjury. However, there were no significant differences between the two groups, implying that LOTUS overexpression did not affect glial scar size (Fig. 2G,H).

\section{LOTUS reduced axonal dieback of CST fibers but did not promote long-distance elongation across the lesion following $\mathrm{SCI}$}

Although the CST is the most important descending pathway for motor function in humans (Lemon, 2008), the effects of NgR1 on CST fibers following SCl are controversial. To examine the influence of LOTUS pan-neuronal overexpression on CST fibers, we injected an anterograde tracer, BDA, into the primary motor cortex of mice in both groups and sacrificed the mice for histologic analysis two weeks after injection. BDA labeling confirmed that CST fibers were present in the dorsal column (dCST) and ipsilateral/contralateral gray matter (ipsilateral/contralateral CST; Fig. 3A; Kim et al., 2003). The dCST extended significantly further into the rostral sites (from 3.0 to 1.0 $\mathrm{mm}$ rostral to the epicenter) in the LOTUS group than in the control group (Fig. 3B,C; $3.0 \mathrm{~mm}$ rostral $p=0.006 ; 2.5$ $\mathrm{mm}$ rostral $p=0.008 ; 2.0 \mathrm{~mm}$ rostral $p=0.033$ ). The dCST in the control group was observed up to $2 \mathrm{~mm}$ rostral from the injury epicenter, whereas the BDApositive area in the LOTUS group was observed up to 0.5 $\mathrm{mm}$ rostral, closer to the epicenter, than that in the control group. The dCST was not detected caudal to the epicenter in either of the groups (Fig. 3B,C). An increase in ipsilateral and contralateral CST fibers was observed with LOTUS overexpression in the rostral sites, with a significant difference in fibers seen in the ipsilateral CST 2 and $2.5 \mathrm{~mm}$ rostral to the epicenter (Fig. 3D,E; $2.5 \mathrm{~mm}$ rostral $p=0.026 ; 2 \mathrm{~mm}$ rostral $p=0.048$ ). These results suggested that LOTUS promoted the increase in the CST fibers rostrally anterior to the lesion due to reduced axonal dieback anterior to the lesion. However, LOTUS could not promote long-distance extension across the lesion area.

\section{LOTUS promotes an increase in reticulospinal} neurons that project axons caudal to the injury site

Although CST fibers failed to regenerate beyond the lesion, we also traced other descending pathways. According to previous studies, the reticulospinal tract may be more important than the CST for motor function in rodents (Ballermann and Fouad, 2006; Lemon, 2008). To trace reticulospinal tract fibers, we injected the retrograde tracer, FG, into the spinal cord caudal to the injury site in both groups of mice. Then, we sacrificed the mice one week after injection and histologically analyzed the reticular formations in the brainstem (Fig. 4A). This analysis revealed a significant increase in the number of FGlabeled reticular nucleus neurons in the LOTUS group (Fig. 4B,C; LOTUS group; $36.93 \pm 7.06$ vs control group; $13.41 \pm 9.88, p=0.004)$. Together, these data demonstrated that a greater number of reticulospinal neurons project axons caudal to the lesion site following $\mathrm{SCl}$ in the LOTUS group than in the control group.

\section{LOTUS contributes to an increase in neuronal fibers in the injured spinal cord}

Following the tracer experiments, we evaluated the effect of pan-neuronal LOTUS overexpression on neuronal fibers in the injured spinal cord through immunohistological analyses. Fifty-six days postinjury, immunostaining was performed using antibodies against neurofilament heavy chain (NF-H) and $5-\mathrm{HT}$, markers for neuronal fibers and the serotonergic raphespinal tract, respectively. The serotonergic raphespinal tract, one of the major descending pathways, is especially important for the motor functional circuitry of hindlimbs (Bregman, 1987; Saruhashi et al., 1996; Kim et al., 1999).

The NF-H-positive area in the axial section of the LOTUS group was significantly larger at and beyond the 
A

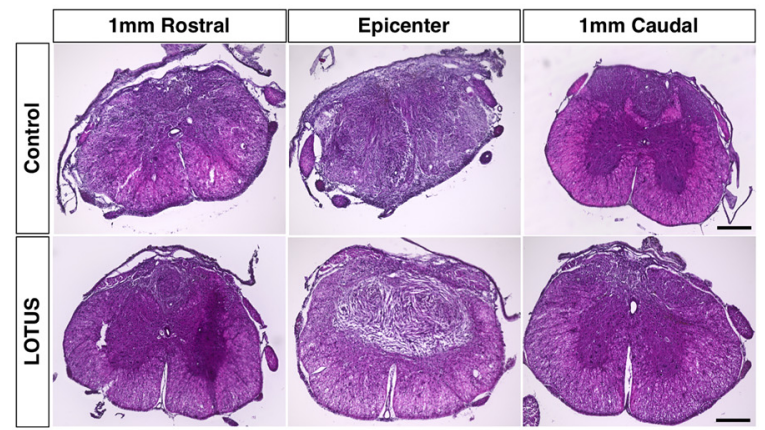

C

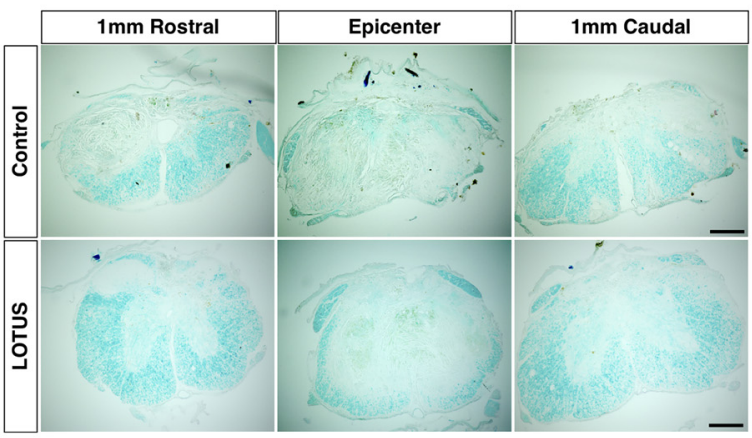

E

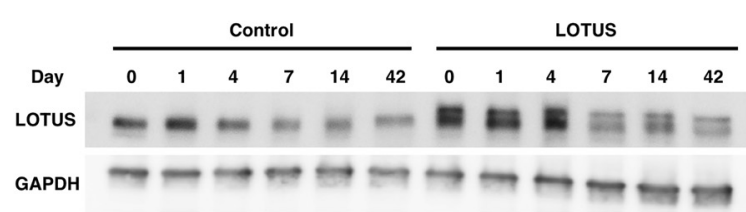

G

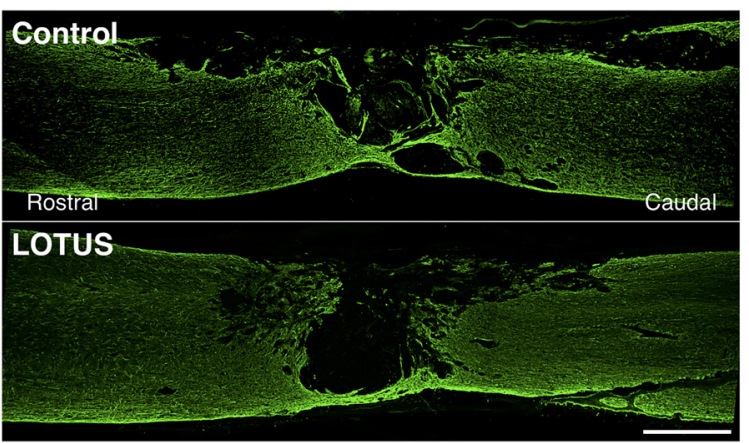

B

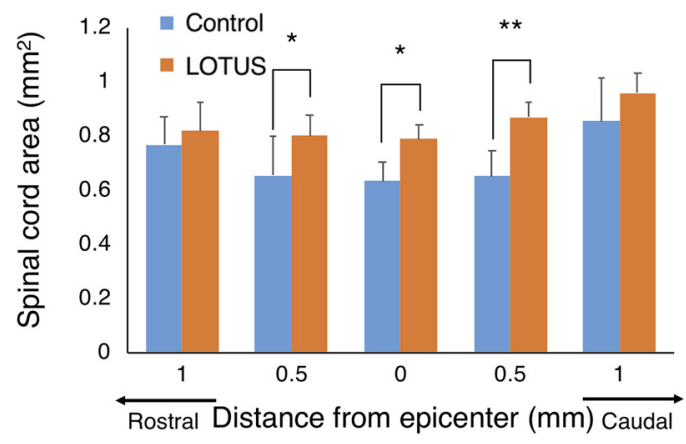

D

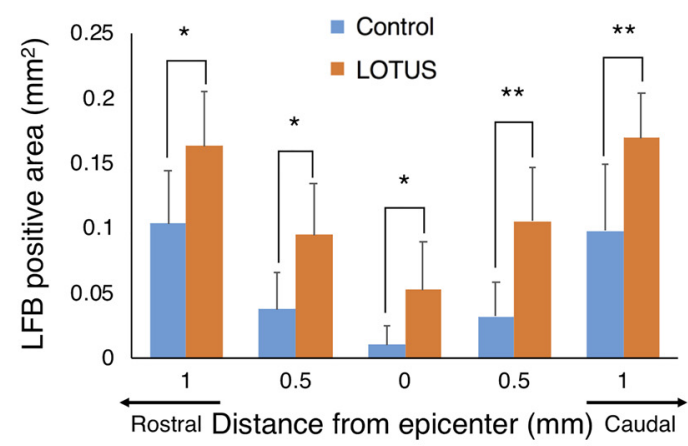

F

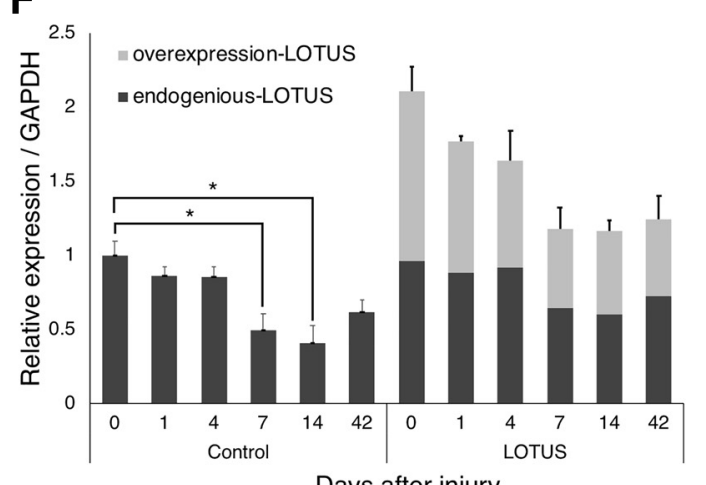

Days after injury

H

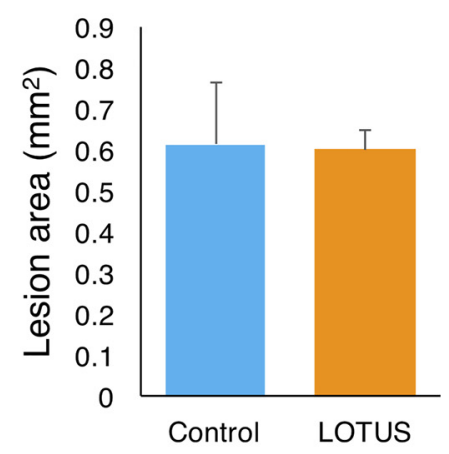

Figure 2. LOTUS minimizes spinal cord atrophy and preserves myelinated nerve fibers after SCI. $\boldsymbol{A}$, Representative images of HE staining in axial sections from $1 \mathrm{~mm}$ rostral to $1 \mathrm{~mm}$ caudal to the epicenter $56 \mathrm{~d}$ after SCl. $\boldsymbol{B}$, Quantitative analysis of the spinal cord area. $\boldsymbol{C}$, Representative images of HE staining in axial sections from $1 \mathrm{~mm}$ rostral to $1 \mathrm{~mm}$ caudal to the epicenter $56 \mathrm{~d}$ after SCI. $\boldsymbol{D}$, Quantitative analysis of the LFB-positive myelinated area. E. Western blot analyses of endogenous and overexpressed LOTUS protein expression in the injured spinal cord. $\boldsymbol{F}$, Quantitative analyses of the time course changes of the expression level of endogenous and overexpressed LOTUS relative to that of GAPDH. G, Representative images of immunostaining for GFAP in sagittal sections $56 \mathrm{~d}$ after 
continued

$\mathrm{SCl}$. $\boldsymbol{H}$, Quantitative analysis of the lesion area size surrounded by reactive astrocytes. Values are the mean $\pm \mathrm{SD} ; * p<0.05, * * p<$ 0.01. Statistical analysis was performed using two-way ANOVA, followed by the Bonferroni multiple comparisons test in $\boldsymbol{B}, \boldsymbol{D}, \boldsymbol{F}$ and unpaired two-tailed Student's $t$ test in $\boldsymbol{H}(n=5$ each). Scale bars: $200 \mu \mathrm{m}(\boldsymbol{A}, \boldsymbol{C})$ and $500 \mu \mathrm{m}(\boldsymbol{G})$.

epicenter than that of the control group (Fig. 5B,C; epicenter $p=0.035 ; 2 \mathrm{~mm}$ caudal $p=0.037 ; 4 \mathrm{~mm}$ caudal $p=0.04)$. The $5-\mathrm{HT}$-positive area was also significantly greater in the LOTUS group from $2 \mathrm{~mm}$ to $4 \mathrm{~mm}$ caudal to the epicenter (Fig. 5D-F; $2 \mathrm{~mm}$ caudal $p=0.04 ; 4 \mathrm{~mm}$ caudal, $p=0.001)$. In the midsagittal sections of the control group, almost no 5-HT-positive fibers extending to the caudal site beyond the lesion were observed. By
A

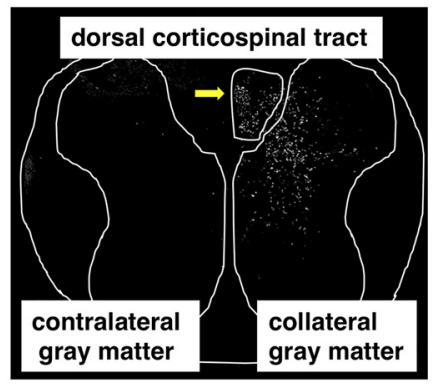

B

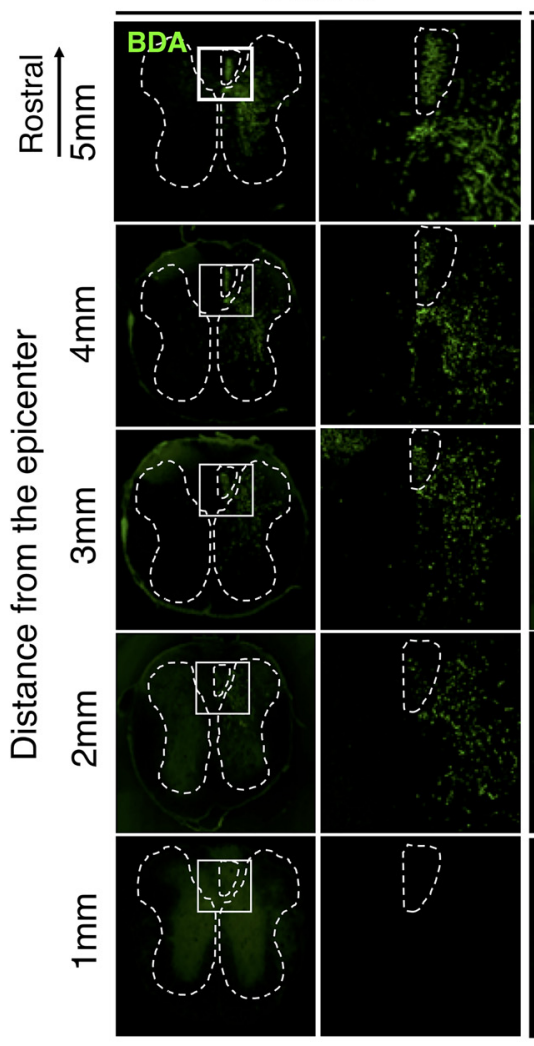

\section{LOTUS}

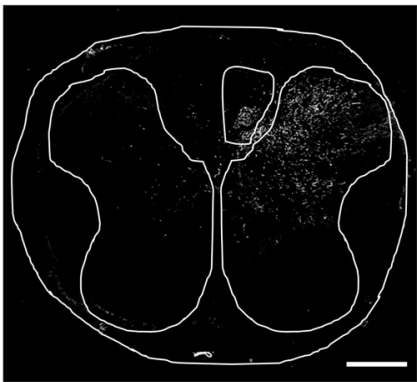

LOTUS

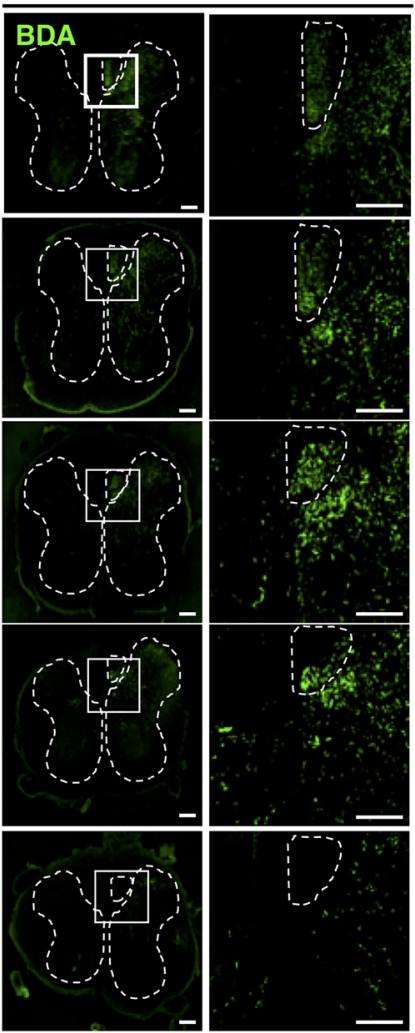

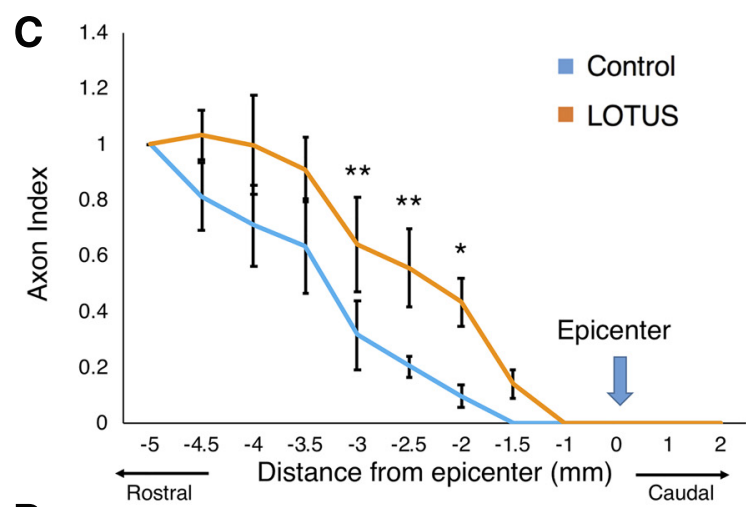

D

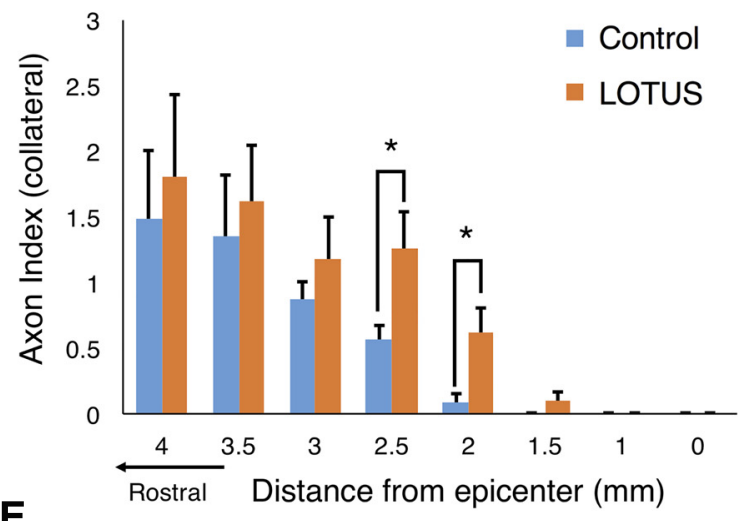

E

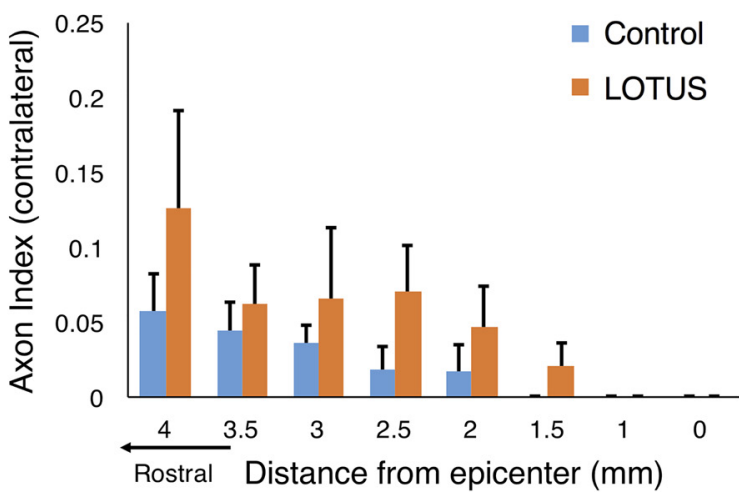

Figure 3. LOTUS reduced axonal dieback in CST fibers following SCI. $\boldsymbol{A}$, A schematic illustration of the dCST and collateral/ contralateral CST in axial sections at $2.5 \mathrm{~mm}$ rostral to the epicenter $56 \mathrm{~d}$ after SCl. $\boldsymbol{B}$, Representative images of CST fibers labeled with BDA in axial sections from $5 \mathrm{~mm}$ to $1 \mathrm{~mm}$ rostral to the epicenter at $56 \mathrm{~d}$ after SCl. The dCST and collateral/contralateral gray matter areas are surrounded by a dotted line. Enlarged images of the area in the white box are shown, and dCST areas were similarly surrounded. C, Quantitative analysis of the dCST fibers (relative to the fibers at $5 \mathrm{~mm}$ rostral) from $5 \mathrm{~mm}$ rostral to the epicenter to sites caudal to the epicenter. $\boldsymbol{D}, \boldsymbol{E}$, Quantitative analyses of the axon index in the ipsilateral/contralateral gray matter CST relative to that in dCST $5 \mathrm{~mm}$ rostral to the epicenter. Values are the mean $\pm \mathrm{SD}$; $* p<0.05$. Statistical analysis was performed using two-way ANOVA, followed by the Bonferroni multiple comparisons test ( $n=5$ each) in $\boldsymbol{C}-\boldsymbol{E}$. Scale bars: $200 \mu \mathrm{m}(\boldsymbol{A})$ and $100 \mu \mathrm{m}(\boldsymbol{B})$. 
A

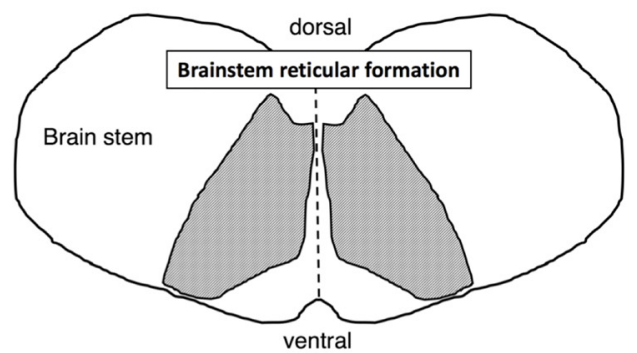

B
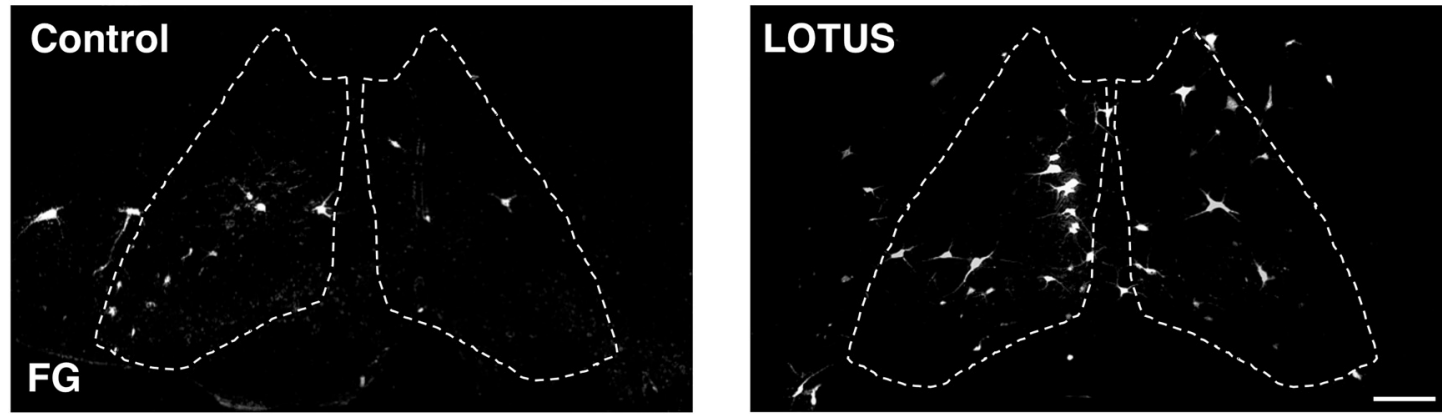

C

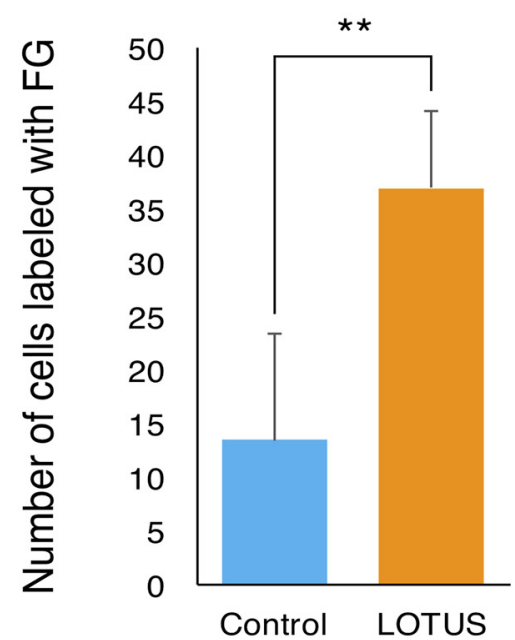

Figure 4. LOTUS increases reticulospinal neurons projecting axons caudal to the lesion following SCl. $\boldsymbol{A}, \mathrm{A}$ schematic illustration of the brainstem reticular formation. $\boldsymbol{B}$, Representative images of reticular nucleus neurons retrogradely labeled with FG. $\boldsymbol{C}, \mathrm{Quantitative}$ analysis of the number of cells labeled with FG. Values are the mean $\pm \mathrm{SD} ; * p<0.05, * * p<0.01$. Statistical analysis was performed using unpaired two-tailed Student's $t$ test $(n=5$ each in $\boldsymbol{C})$. Scale bars: $100 \mu \mathrm{m}(\boldsymbol{B})$.

contrast, in the LOTUS group, many fibers were seen at the caudal site, and fibers were also detectable in the lesion epicenter (Fig. 5G-J).

\section{LOTUS enhances raphespinal tract regeneration}

Although we revealed that LOTUS overexpression led to an increase in NF-H-positive and raphespinal tract fibers $56 \mathrm{~d}$ postinjury, whether this increase resulted from neuronal protection against secondary injury or the regen- eration of neuronal fibers at the chronic stage was unclear. To address this issue, we examined 5-HT-positive raphespinal tract fibers in more detail.

We immunohistochemically analyzed raphespinal tract fibers in axial sections $4 \mathrm{~mm}$ caudal to the epicenter at 14 and $56 \mathrm{~d}$ postinjury (Fig. 6A). At $14 \mathrm{~d}$ postinjury, a larger 5-HT-positive area was observed in the LOTUS group than in the control group $(p=0.035)$. Notably, a significant increase was detected between 14 and 56 d postin- 
A \& B

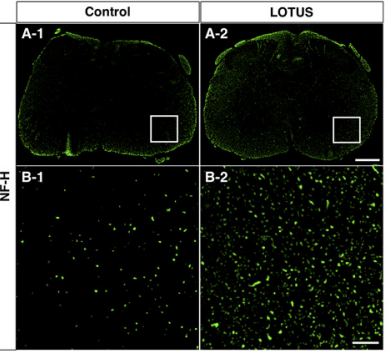

D \& $E$

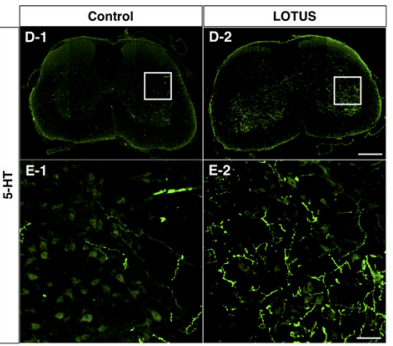

C

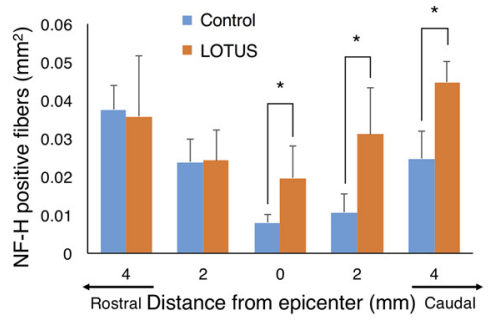

F

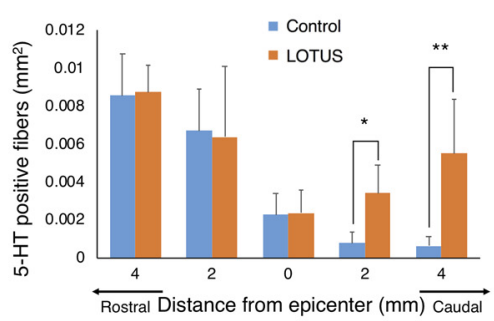

\section{G-J}

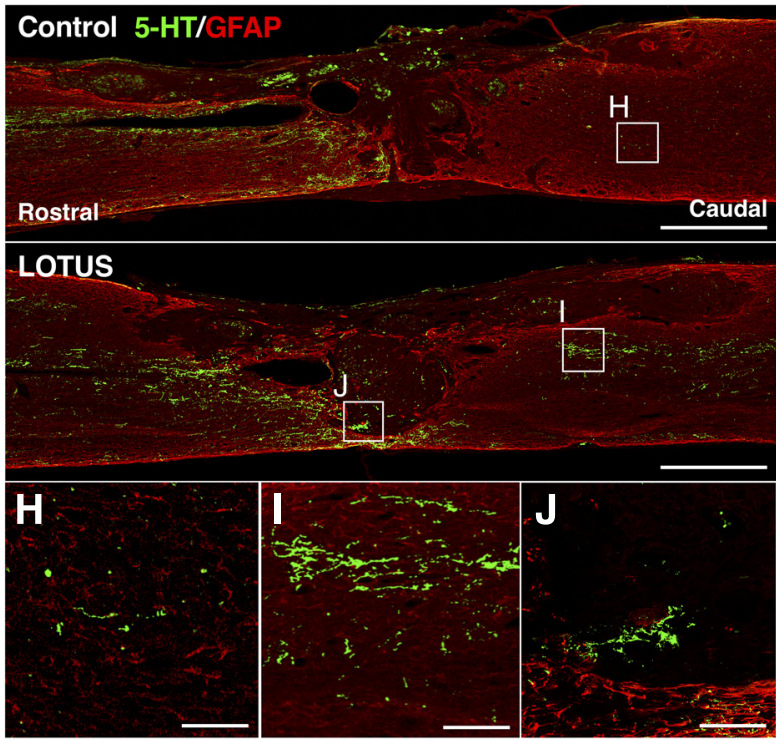

Figure 5. LOTUS promotes the regeneration of NF-H- and 5-HT-positive fibers. $\boldsymbol{A}$, Representative images of immunostaining for $\mathrm{NF}-\mathrm{H}$ in axial sections at $4 \mathrm{~mm}$ caudal to the epicenter $56 \mathrm{~d}$ after SCI. $\boldsymbol{B}$, Enlarged images of $\mathrm{NF}-\mathrm{H}$-positive fibers of the area in the white box in $\boldsymbol{A}$. C, Quantitative analysis of NF-H-positive fibers from $4 \mathrm{~mm}$ rostral to $4 \mathrm{~mm}$ caudal to the epicenter. $\boldsymbol{D}$, Representative images of immunostaining for 5-HT in axial sections at $4 \mathrm{~mm}$ caudal to the epicenter $56 \mathrm{~d}$ after SCl. $\boldsymbol{E}$, Enlarged images of 5-HT-positive fibers of the area in the white box in $\boldsymbol{D}$. $\boldsymbol{F}$, Quantitative analysis of the $5-\mathrm{HT}$-positive fibers from $4 \mathrm{~mm}$ rostral to $4 \mathrm{~mm}$ caudal to the epicenter. $\boldsymbol{G}$, Representative images of immunostaining for 5 -HT/GFAP in sagittal sections $56 \mathrm{~d}$ after $\mathbf{S C l}$. $\boldsymbol{H}-\boldsymbol{J}$, Enlarged images of the area in the white box in $\mathbf{G}$. Values are the mean $\pm \mathrm{SD} ; * p<0.05$. Statistical analysis was performed using two-way ANOVA, followed by the Bonferroni multiple comparisons test $(n=5$ each). Scale bars: $200 \mu \mathrm{m}(\boldsymbol{A}, \boldsymbol{D}), 50 \mu \mathrm{m}(\boldsymbol{B}, \boldsymbol{E}, \boldsymbol{H}-\boldsymbol{J})$, and $500 \mu \mathrm{m}(\boldsymbol{G})$.

jury in the LOTUS group (14 vs $56 \mathrm{~d} p=0.002$; control vs LOTUS at $56 \mathrm{~d} p=0.000)$, while this trend was not observed in the control group ( $p=0.827$; Fig. $6 B$ ). Taken together, these results indicated that LOTUS enhanced the regeneration of raphespinal tract fibers.

Furthermore, we performed immunostaining of phosphorylated growth-associated protein 43 (pGAP43), a growth cone marker that provides an indication of nerve regeneration (Fukura et al., 2000; Fig. 6C,D). In axial sections $4 \mathrm{~mm}$ caudal to the epicenter at $56 \mathrm{~d}$ postinjury, the pGAP43-positive area was significantly larger in the LOTUS group than in the control group (Fig. $6 E ; p=0.023$ ). Double immunostaining with 5-HT and pGAP43 antibodies in the midsagittal sections of the LOTUS group showed partial coexpression of pGAP43 in 5-HT-positive fibers (Fig. 6F). These results strongly suggested that LOTUS promoted the regeneration of the raphespinal tract following injury.

\section{LOTUS suppresses injury-induced apoptotic cell death}

Our data have demonstrated that LOTUS overexpression minimizes spinal cord atrophy, preserves the myelinated area, and promotes the regeneration of raphespinal tract fibers following early injury (Figs. $2 A, C, 6 A, B$ ), suggesting that LOTUS protects spinal cord tissue, including neuronal fibers, following injury. Immunostaining of cleaved caspase-3, a marker for apoptosis, revealed apoptotic cells at the margin of the lesion $7 \mathrm{~d}$ postinjury in both groups (Fig. 7A), and quantitative analyses revealed that the LOTUS group expressed significantly fewer apo- ptotic cells (Fig. $7 B, C ; p=0.016$ ). Additionally, we performed TUNEL staining at $7 \mathrm{~d}$ postinjury, which showed a decrease in TUNEL-positive apoptotic cells in the LOTUS group (Fig. $7 D, E ; p=0.004$ ). These results suggested that apoptosis at the acute phase of $\mathrm{SCl}$ was prevented by LOTUS overexpression.

\section{LOTUS promotes the recovery of motor function and nerve conduction}

Motor functional recovery following $\mathrm{SCl}$ was assessed using the BMS scoring system, rota-rod test and DigiGait footprint analysis. The BMS scores in the LOTUS group were significantly better than those in the control group at one week following $\mathrm{SCl}$ and thereafter (Fig. 8A). Furthermore, the LOTUS group exhibited a significantly longer total run time in the rota-rod test $42 \mathrm{~d}$ post-SCl (Fig. 8B; $p=0.001$ ). In the treadmill gait analyses using DigiGait, a significantly longer hindlimb stride length and narrower hindlimb stance angle were seen in the LOTUS group than in the control group 42 d postinjury (Fig. $8 C$; stride length $p=0.004$; stance angle $p=0.013$ ). Phase dispersion, an indicator of coordination measured using DigiGait analysis, showed that the LOTUS group exhibited significantly better hindlimb coordination than did the control group (Fig. 8D). Although there was no significant difference, electrophysiological analysis revealed motor evoked potential (MEP) waves in $80 \%$ of the LOTUS group and $50 \%$ of the control group at final follow-up. Moreover, we found a significantly shorter MEP latency and larger MEP amplitude in the LOTUS group (Fig. $6 E, F$; latency $p=0.049$; amplitude $p=0.017$ ), indicating a potential benefit of 
A

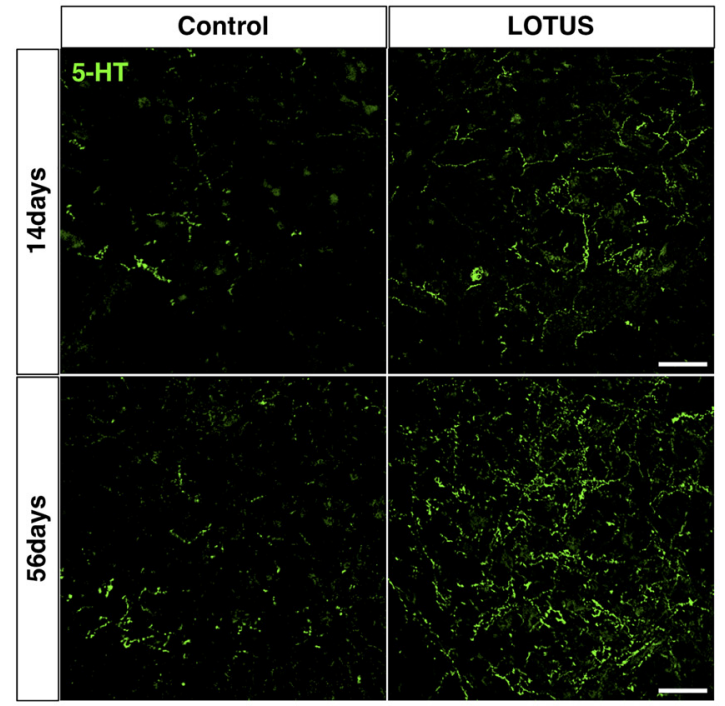

C \& D

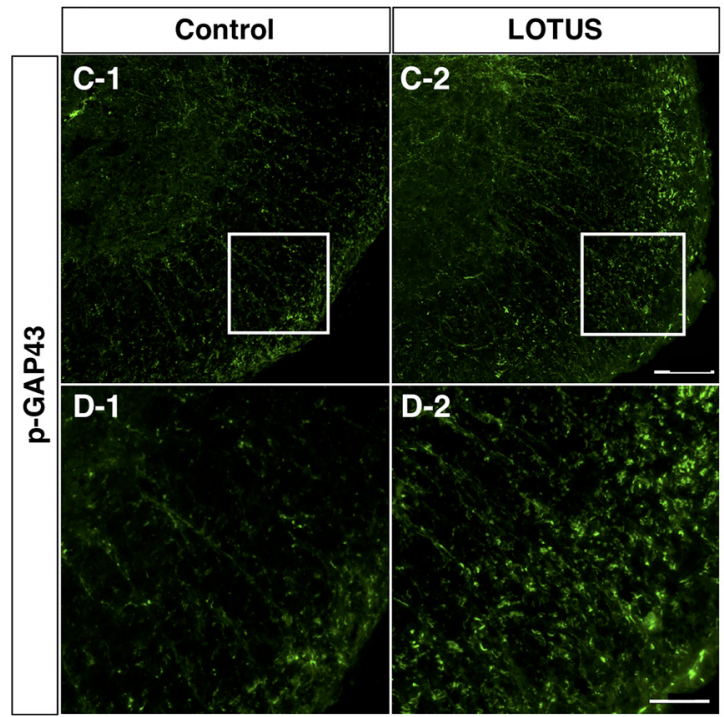

B

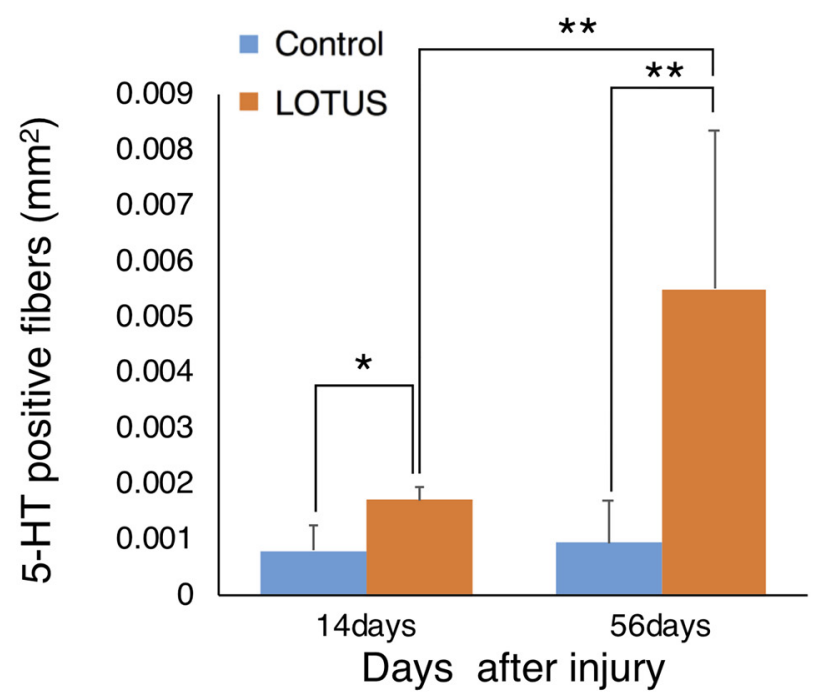

E

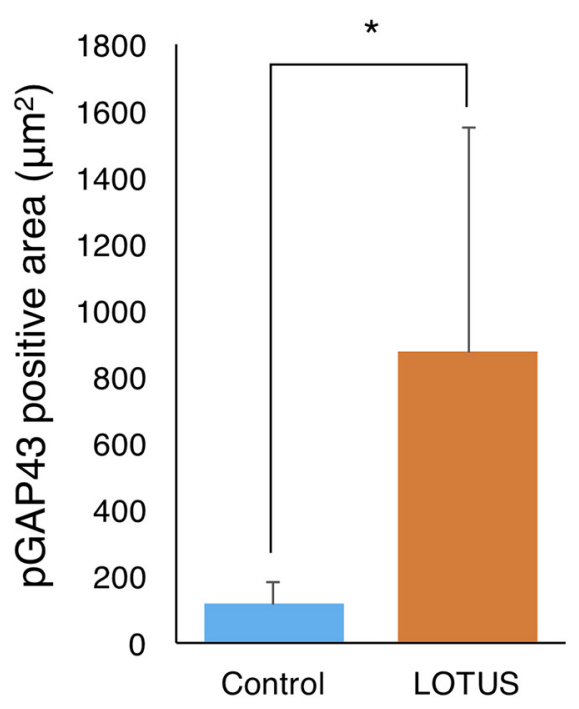

F
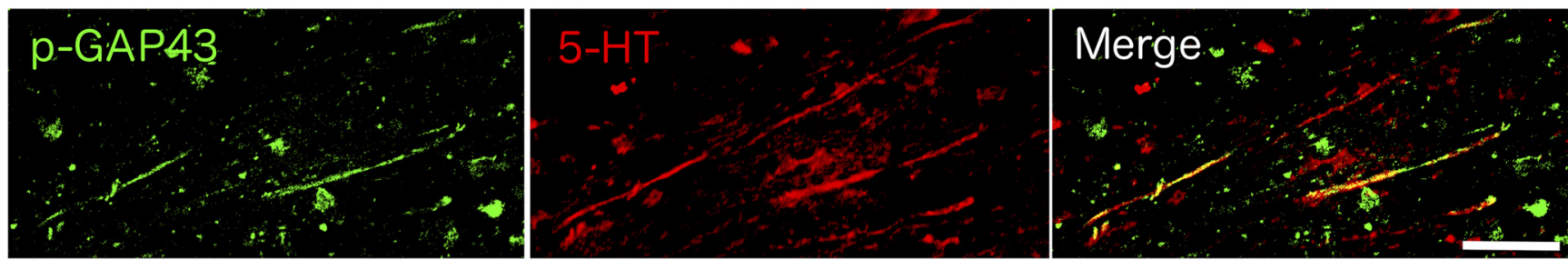

Figure 6. LOTUS promotes the regeneration and protection of 5-HT-positive fibers caudal to the epicenter after SCI. $\boldsymbol{A}$, Representative images of immunostaining for $5-\mathrm{HT}$ in axial sections at $4 \mathrm{~mm}$ caudal to the epicenter 14 and $56 \mathrm{~d}$ after SCI. $\boldsymbol{B}$, Quantitative analysis of 5-HT-positive fibers 14 and $56 \mathrm{~d}$ after $\mathrm{SCl}$. $\boldsymbol{C}$, Representative images of immunostaining for p-GAP43 in axial sections at $4 \mathrm{~mm}$ caudal to the epicenter $56 \mathrm{~d}$ after SCI. $\boldsymbol{D}$, Enlarged images of NF-H-positive fibers in the area surrounded by the white box in $\boldsymbol{C}$. $\boldsymbol{E}$, Quantitative analysis of the p-GAP43-positive fibers. $\boldsymbol{F}$, Representative images of double immunostaining for p-GAP43 and $5-\mathrm{HT}$. Values are the mean $\pm \mathrm{SD} ; * p<0.05$. Statistical analysis was performed using two-way ANOVA, followed by the Bonferroni multiple comparisons test in $\boldsymbol{B}$ and unpaired two-tailed Student's $t$ test in $\boldsymbol{E}(n=4$ each at day $14, n=5$ each at day 56 after SCl in $B, n=4$ each in $\boldsymbol{E})$. Scale bars: $50 \mu \mathrm{m}(\boldsymbol{A}, \boldsymbol{D}, \boldsymbol{F})$ and $100 \mu \mathrm{m}(\boldsymbol{C})$. 
A

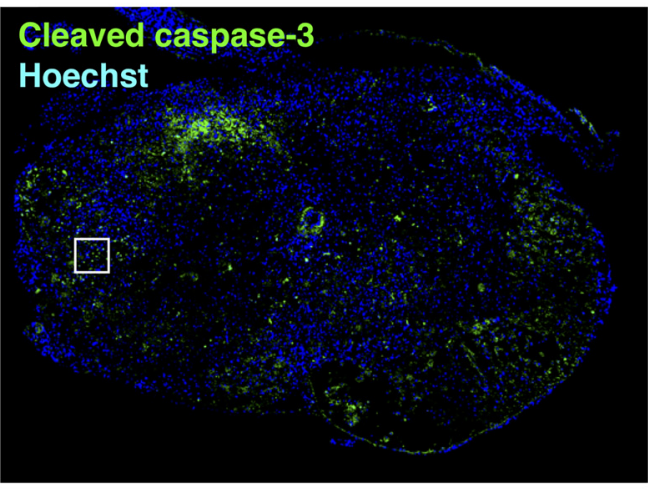

Cleaved caspase-3

Hoechst

B

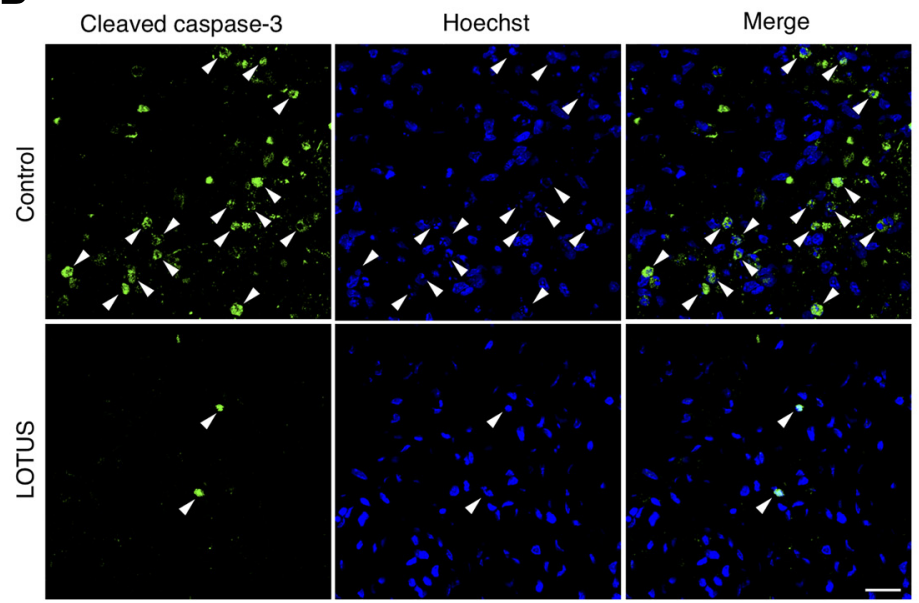

\section{LOTUS}

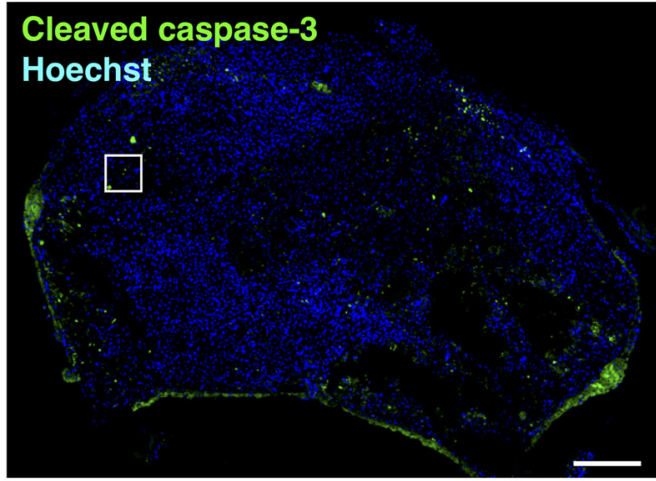

C

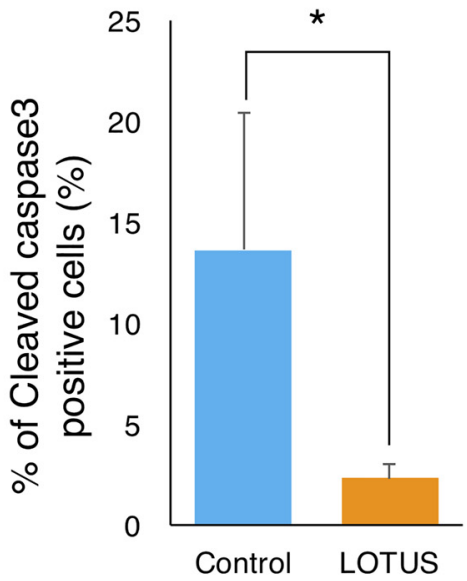

D

E
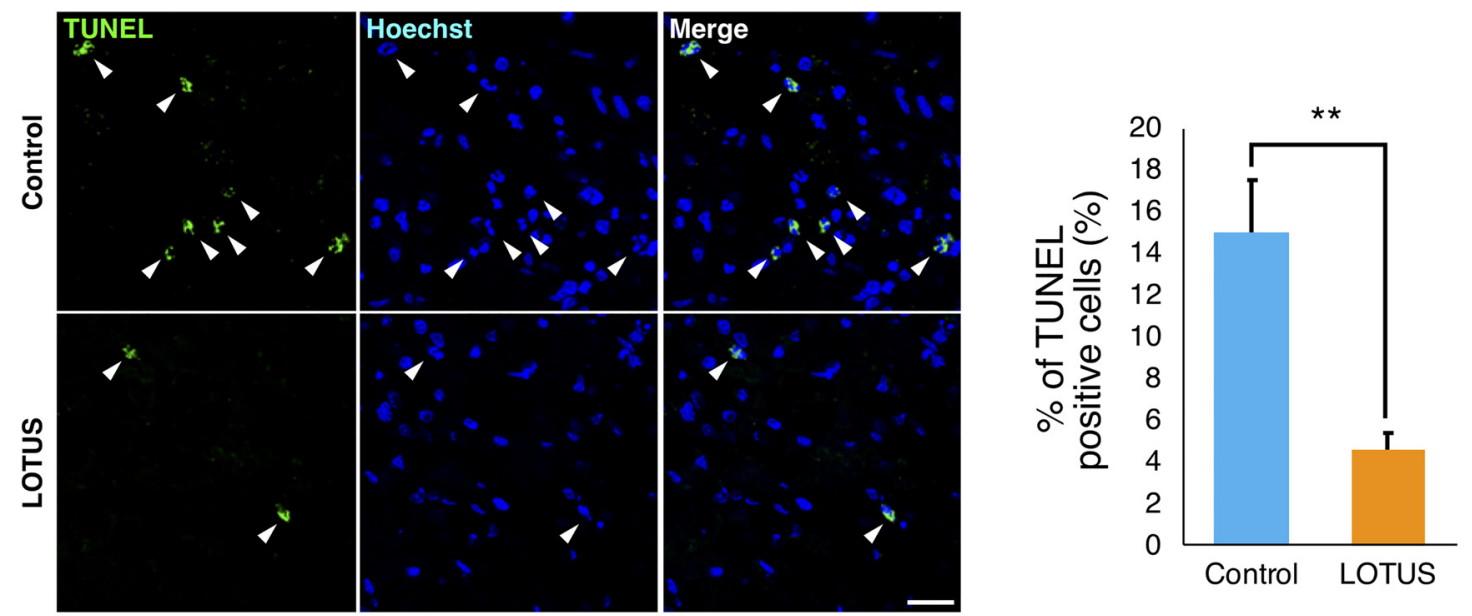

Figure 7. LOTUS suppresses apoptotic cell death at the acute injury phase. $\boldsymbol{A}$, Representative images of apoptotic cells immunostained for cleaved caspase-3 in axial sections at the epicenter $7 \mathrm{~d}$ after SCl. B, Enlarged images of the margin of the epicenter (white box in $\boldsymbol{A}$; green: cleaved caspase-3, blue: nucleus). The arrows indicate apoptotic nuclei stained for cleaved caspase-3. $\boldsymbol{C}$, Quantitative analysis of the percentage of apoptotic cells. $\boldsymbol{D}$, Representative images of TUNEL staining in axial sections at the epicenter $7 \mathrm{~d}$ after SCI. E, Quantitative analysis of the percentage of TUNEL-positive cells. Values are the mean $\pm \mathrm{SD} ; * p<0.05, * * p$ $<$ 0.01. Statistical analysis was performed using unpaired two-tailed Student's $t$ test $(n=3$ each). Scale bars: $200 \mu \mathrm{m}(\boldsymbol{A}), 50 \mu \mathrm{m}(\boldsymbol{B})$, and $20 \mu \mathrm{m}(\boldsymbol{D})$. 
A

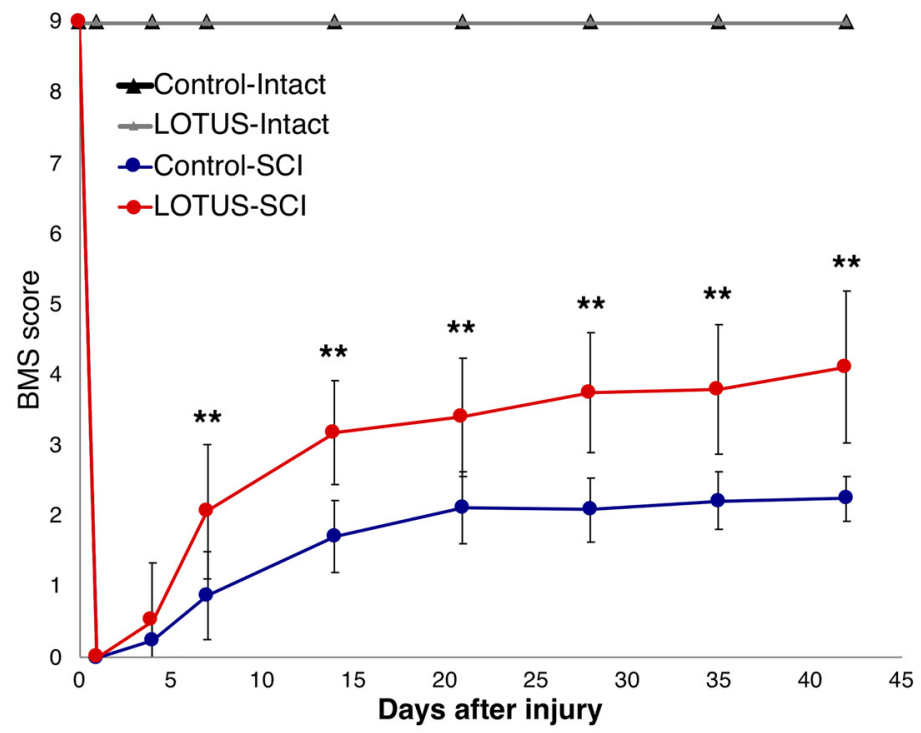

B

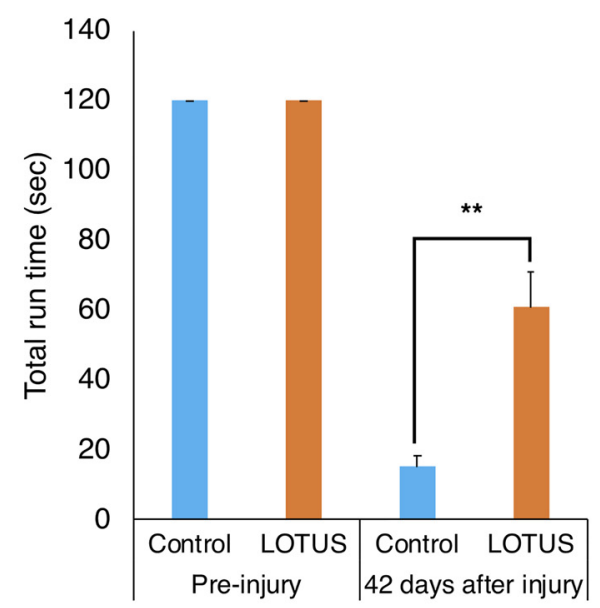

C

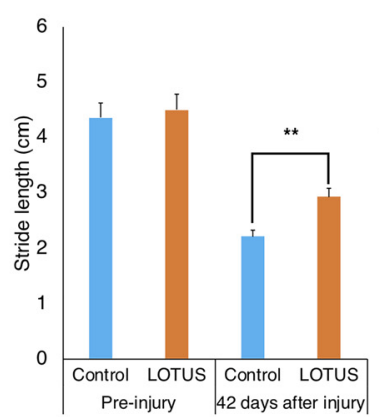

E

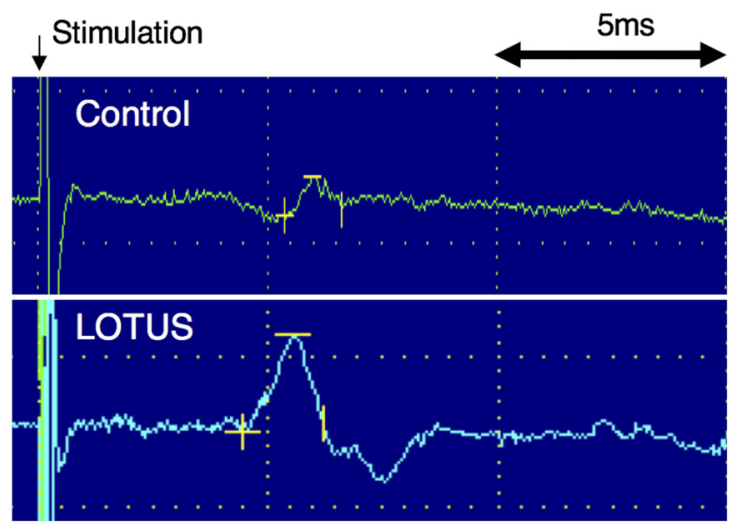

D
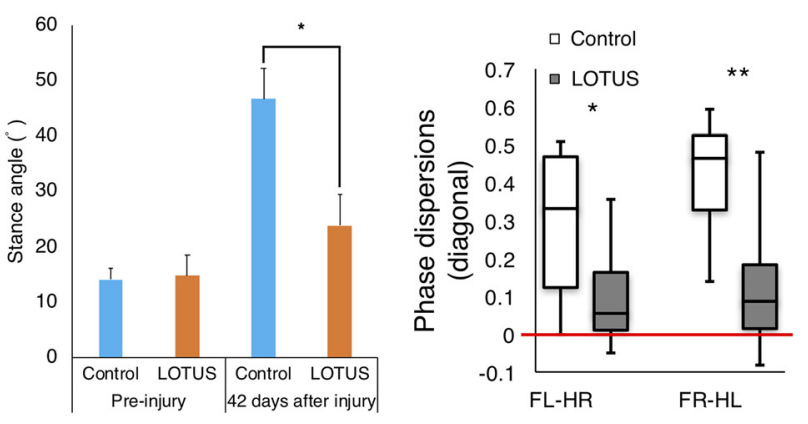

F

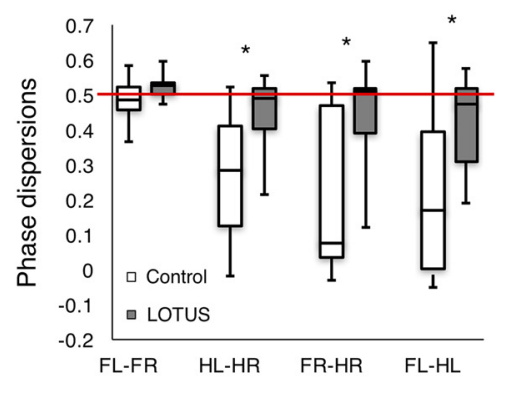

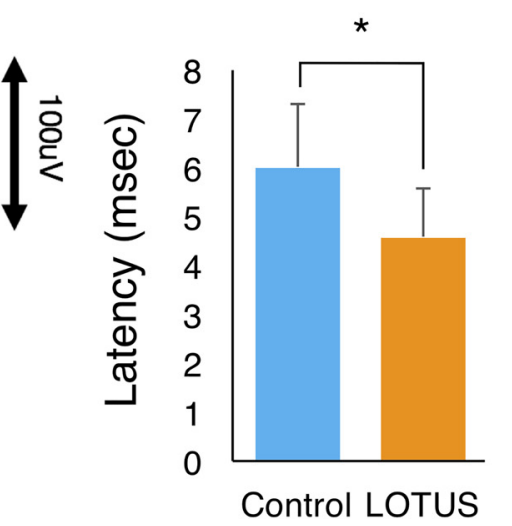

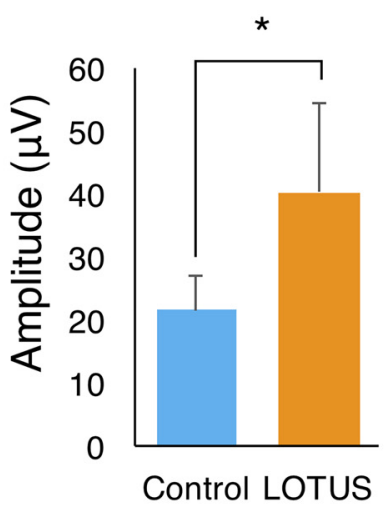

Figure 8. Evaluation of motor functional recovery and MEP waves. $\boldsymbol{A}$, Hindlimb motor function was evaluated weekly for six weeks after SCI by BMS scores in the control and LOTUS groups (intact model, control group; $n=5$, LOTUS group; $n=5$, SCI model, control group; $n=16$, LOTUS group; $n=20$ ). $\boldsymbol{B}$, The rota-rod test was performed $42 \mathrm{~d}$ after SCl, and total run time was quantitatively analyzed (preinjury; $n=5$ each, control group; $n=9$, LOTUS group; $n=10$ ). $\boldsymbol{C}$, Treadmill gait analyses using a DigiGait System were examined $42 \mathrm{~d}$ after $\mathrm{SCl}$, and quantitative analyses of the stride length and stance angle were performed (preinjury; $n=5$ each, control group; $n=9$, LOTUS group; $n=14$ ). $\boldsymbol{D}$, Hindlimb coordination was analyzed by phase dispersions in DigiGait analyses (control group; $n=9$, LOTUS group; $n=14)$. $\boldsymbol{E}$, Electrophysiological analysis of MEP waves was performed $56 \mathrm{~d}$ after SCl, and representative images are shown ( $n=10$ each). $\boldsymbol{F}$, Quantitative analyses of the latency and amplitude were performed (control group; $n=5$, LOTUS group; $n=8)$. Values are the mean $\pm \mathrm{SD} ; * p<0.05, * * p<0.01$. Statistical analysis was performed using unpaired two-tailed Student's $t$ test in the rota-rod test, DigiGait analyses, MEP analysis and two-way repeated-measures ANOVA with Tukey's test in the analysis of the BMS score. 
LOTUS pan-neuronal overexpression for the improvement in nerve conduction.

\section{Discussion}

In this study, we evaluated the therapeutic benefits of LOTUS pan-neuronal overexpression in the injured spinal cord using a clinically relevant contusive $\mathrm{SCI}$ model. Here, we showed that LOTUS has a neuroprotective effect on the spinal cord through reducing cellular apoptosis during the acute phase following SCl. Histologic evaluation of descending motor fiber tracts revealed that LOTUS overexpression enhanced raphespinal axonal regeneration across the lesion area to the caudal site during the chronic stage, increased reticulospinal neurons projecting axons caudal to the lesion and reduced axonal dieback of the CST rostrally anterior to the lesion. However, the longdistance elongation of the CST was not observed beyond the edge of the caudal lesion site. The neural preservation and regeneration activity of LOTUS may have contributed to the significant motor functional recovery observed in these mice. Thus, administration of LOTUS in the treatment of $\mathrm{SCl}$ could be a promising strategy through promoting endogenous restoration and locomotor improvement.

Detailed histologic analyses revealed remarkable effects of LOTUS overexpression on raphespinal tract regeneration. Although the raphespinal tract is known for its modulatory effects on sensory activity (Mason, 2001), it can function as a detour circuit, connecting to the motor circuit after SCl (Liang et al., 2015). In fact, a previous study using the serotonergic neurotoxin 5,7-dihydroxytryptamine showed that raphespinal regeneration following $\mathrm{SCl}$ significantly contributed to functional recovery in NgR1-lacking mice (Kim et al., 2004) and Semaphorin 3A (Sema3A) inhibitor-treated rats (Kaneko et al., 2006), thereby substantiating our results that demonstrated a favorable effect of the NgR1 antagonist on the tract. Furthermore, Hirokawa et al. (2017) reported that panneuronally LOTUS-overexpressing transgenic mice obtained significantly enhanced motor functional recovery with the increase in 5-HT positive raphespinal tract fibers after injury, whereas LOTUS-deficient mice obtained less functional recovery than did control mice with the decrease in raphespinal tract fibers. These results suggested that raphespinal tract regeneration was relevant to locomotor recovery, and the present study also supported this hypothesis.

Alternatively, a retrograde tracing study demonstrated that LOTUS expression may contribute to the increase in reticulospinal neurons that project axons caudal to the lesion postinjury. No study has clarified the relationship between the regeneration of the reticulospinal tract and $\mathrm{NgR} 1$ in the injured spinal cord. This tract is implicated in central pattern generators responsible for locomotion generation (Fink and Cafferty, 2016) and mediates the fastest descending excitation observed in motoneurons (Alstermark et al., 2004). It is possible that LOTUS increased reticulospinal tract fibers, which may be intimately associated with neurologic restoration after $\mathrm{SCl}$. Further studies of the phenotype and time course changes postinjury are needed to elucidate the regenerative effect of LOTUS on the reticulospinal tract.

In pan-neuronally LOTUS-overexpressing mice, we observed a reduction in cellular apoptosis and an increase in neuronal fiber preservation in the subacute phase of SCl. This neural preservation led to an earlier motor functional recovery in the BMS score in LOTUS-overexpressing mice than in control mice. Similarly, administration of Nogo-66 antagonist peptide (NEP1-40), an NgR1 antagonist, also showed neuroprotective effects via inhibition of neuronal apoptosis after cerebral ischemic injury (Wang et al., 2008). However, little is known about the mechanism by which NgR1 signaling affects cellular apoptosis after CNS injury. To clarify this question, a previous study revealed that activated NgR1 following brain ischemia led to activation of the Rho-A and ROCK pathways, which induced neuronal apoptosis (Zhang et al., 2007). Furthermore, administration of a Rho-A inhibitor suppressed apoptosis in a SCl model (Dubreuil et al., 2003). The Rho-A inhibitor blocked the conversion of Rho-guanosine diphosphate (GDP) to Rho-guanosine triphosphate (GTP) and activation of p75 neurotrophin receptor ( $p 75^{\mathrm{NTR}}$ ), thereby blocking $\mathrm{p} 75^{\mathrm{NTR}}$-dependent apoptosis. Therefore, $\mathrm{NgR} 1$ may play an important role in $\mathrm{SCl}$-induced apoptosis.

In the present study, we evaluated the efficacy of LOTUS overexpression in neuronal protection, axonal regeneration and functional recovery using a contusive $\mathrm{SCl}$ model. Transection models are most often used to examine axonal extension after $\mathrm{SCl}$ because of the resulting clearly defined lesion area, especially in most previous reports that evaluated axonal regeneration through $\mathrm{NgR}$ inhibition. However, these models do not represent the common injury mechanisms found in the clinical setting (Forgione et al., 2017). SCl is largely caused by contusion and compression injuries, which are followed by primary and secondary injury phases. Therefore, selecting a more clinically relevant contusion model is extremely important for preclinical trials when evaluating the protective and regenerative effects of injury during the inflammatory phase (Kwon et al., 2011).

In conclusion, we have demonstrated that pan-neuronal LOTUS overexpression enhances neuronal protection, axonal regeneration and functional recovery after a more clinically relevant contusive SCI model. LOTUS exerts a strong inhibitory action against $\mathrm{NgR} 1$ and may represent a therapeutic strategy for $\mathrm{SCl}$.

\section{References}

Alstermark B, Ogawa J, Isa T (2004) Lack of monosynaptic corticomotoneuronal EPSPs in rats: disynaptic EPSPs mediated via reticulospinal neurons and polysynaptic EPSPs via segmental interneurons. J Neurophysiol 91:1832-1839. CrossRef Medline

Ballermann M, Fouad K (2006) Spontaneous locomotor recovery in spinal cord injured rats is accompanied by anatomical plasticity of reticulospinal fibers. Eur J Neurosci 23:1988-1996. CrossRef Medline

Bartsch U, Bandtlow CE, Schnell L, Bartsch S, Spillmann AA, Rubin BP, Hillenbrand R, Montag D, Schwab ME, Schachner M (1995) Lack of evidence that myelin-associated glycoprotein is a major inhibitor of axonal regeneration in the CNS. Neuron 15:1375-1381. Medline 
Basso DM, Fisher LC, Anderson AJ, Jakeman LB, McTigue DM, Popovich PG (2006) Basso Mouse Scale for locomotion detects differences in recovery after spinal cord injury in five common mouse strains. J Neurotrauma 23:635-659. CrossRef Medline

Bregman BS (1987) Spinal cord transplants permit the growth of serotonergic axons across the site of neonatal spinal cord transection. Brain Res 431:265-279. Medline

Dickendesher TL, Baldwin KT, Mironova YA, Koriyama Y, Raiker SJ, Askew KL, Wood A, Geoffroy CG, Zheng B, Liepmann CD, Katagiri Y, Benowitz LI, Geller HM, Giger RJ (2012) NgR1 and NgR3 are receptors for chondroitin sulfate proteoglycans. Nat Neurosci 15: 703-712. CrossRef Medline

Domeniconi M, Cao Z, Spencer T, Sivasankaran R, Wang K, Nikulina E, Kimura N, Cai H, Deng K, Gao Y, He Z, Filbin M (2002) Myelinassociated glycoprotein interacts with the Nogo66 receptor to inhibit neurite outgrowth. Neuron 35:283-290. Medline

Dubreuil Cl, Winton MJ, McKerracher L (2003) Rho activation patterns after spinal cord injury and the role of activated Rho in apoptosis in the central nervous system. J Cell Biol 162:233-243. CrossRef Medline

Fink KL, Cafferty WB (2016) Reorganization of intact descending motor circuits to replace lost connections after injury. Neurotherapeutics 13:370-381. CrossRef Medline

Forgione N, Chamankhah M, Fehlings MG (2017) A mouse model of bilateral cervical contusion-compression spinal cord injury. J Neurotrauma 34:1227-1239. CrossRef Medline

Fournier AE, GrandPre T, Strittmatter SM (2001) Identification of a receptor mediating Nogo-66 inhibition of axonal regeneration. Nature 409:341-346. CrossRef Medline

Fukura H, Kitani Y, Komiya Y, Igarashi M (2000) Nitrous oxide, but not xenon, affects the signaling in the neuronal growth cone. Prog Neuropsychopharmacol Biol Psychiatry 24:1357-1368. Medline

GrandPré T, Nakamura F, Vartanian T, Strittmatter SM (2000) Identification of the Nogo inhibitor of axon regeneration as a Reticulon protein. Nature 403:439-444. CrossRef Medline

Hirokawa T, Zou Y, Kurihara Y, Jiang Z, Sakakibara Y, Ito H, Funakoshi K, Kawahara N, Goshima Y, Strittmatter SM, Takei K (2017) Regulation of axonal regeneration by the level of function of the endogenous Nogo receptor antagonist LOTUS. Sci Rep 7:12119. CrossRef Medline

Ji B, Case LC, Liu K, Shao Z, Lee X, Yang Z, Wang J, Tian T, Shulga-Morskaya S, Scott M, He Z, Relton JK, Mi S (2008) Assessment of functional recovery and axonal sprouting in oligodendrocyte-myelin glycoprotein (OMgp) null mice after spinal cord injury. Mol Cell Neurosci 39:258-267. CrossRef Medline

Kaneko S, Iwanami A, Nakamura M, Kishino A, Kikuchi K, Shibata S, Okano HJ, Ikegami T, Moriya A, Konishi O, Nakayama C, Kumagai K, Kimura T, Sato Y, Goshima Y, Taniguchi M, Ito M, He Z, Toyama Y, Okano H (2006) A selective Sema3A inhibitor enhances regenerative responses and functional recovery of the injured spinal cord. Nat Med 12:1380-1389. CrossRef Medline

Kawakami Y, Kurihara Y, Saito Y, Fujita Y, Yamashita T, Takei K (2018) The soluble form of LOTUS inhibits Nogo receptormediated signaling by interfering with the interaction between Nogo receptor type 1 and p75 neurotrophin receptor. Neuroscience Letters 683:61-68.

Kim D, Adipudi V, Shibayama M, Giszter S, Tessler A, Murray M, Simansky KJ (1999) Direct agonists for serotonin receptors enhance locomotor function in rats that received neural transplants after neonatal spinal transection. J Neurosci 19:6213-6224. CrossRef

Kim JE, Li S, GrandPré T, Qiu D, Strittmatter SM (2003) Axon regeneration in young adult mice lacking Nogo-A/B. Neuron 38: 187-199. Medline

Kim JE, Liu BP, Park JH, Strittmatter SM (2004) Nogo-66 receptor prevents raphespinal and rubrospinal axon regeneration and limits functional recovery from spinal cord injury. Neuron 44:439-451. CrossRef Medline

Kurihara Y, Arie Y, Iketani M, Ito H, Nishiyama K, Sato Y, Nakamura F, Mizuki N, Goshima Y, Takei K (2012) The carboxyl-terminal region of Crtac1B/LOTUS acts as a functional domain in endogenous antagonism to Nogo receptor-1. Biochem Biophys Res Commun 418:390-395. CrossRef Medline

Kurihara Y, Iketani M, Ito H, Nishiyama K, Sakakibara Y, Goshima Y, Takei K (2014) LOTUS suppresses axon growth inhibition by blocking interaction between Nogo receptor- 1 and all four types of its ligand. Mol Cell Neurosci 61:211-218. CrossRef Medline

Kurihara Y, Saito Y, Takei K (2017) Blockade of chondroitin sulfate proteoglycans-induced axonal growth inhibition by LOTUS. Neuroscience 356:265-274. CrossRef Medline

Kwon BK, Okon EB, Tsai E, Beattie MS, Bresnahan JC, Magnuson DK, Reier PJ, McTigue DM, Popovich PG, Blight AR, Oudega M, Guest JD, Weaver LC, Fehlings MG, Tetzlaff W (2011) A grading system to evaluate objectively the strength of pre-clinical data of acute neuroprotective therapies for clinical translation in spinal cord injury. J Neurotrauma 28:1525-1543. CrossRef Medline

Lemon RN (2008) Descending pathways in motor control. Annu Rev Neurosci 31:195-218. CrossRef Medline

Liang H, Wang S, Francis R, Whan R, Watson C, Paxinos G (2015) Distribution of raphespinal fibers in the mouse spinal cord. Mol Pain 11:42. CrossRef Medline

Mason P (2001) Contributions of the medullary raphe and ventromedial reticular region to pain modulation and other homeostatic functions. Annu Rev Neurosci 24:737-777. CrossRef Medline

McKerracher L, David S, Jackson DL, Kottis V, Dunn RJ, Braun PE (1994) Identification of myelin-associated glycoprotein as a major myelin-derived inhibitor of neurite growth. Neuron 13:805-811. Medline

Nishimura S, Yasuda A, Iwai H, Takano M, Kobayashi Y, Nori S, Tsuji O, Fujiyoshi K, Ebise H, Toyama Y, Okano H, Nakamura M (2013) Time-dependent changes in the microenvironment of injured spinal cord affects the therapeutic potential of neural stem cell transplantation for spinal cord injury. Mol Brain 6:3. CrossRef Medline

Nori S, Okada Y, Yasuda A, Tsuji O, Takahashi Y, Kobayashi Y, Fujiyoshi K, Koike M, Uchiyama Y, Ikeda E, Toyama Y, Yamanaka S, Nakamura M, Okano H (2011) Grafted human-induced pluripotent stem-cell-derived neurospheres promote motor functional recovery after spinal cord injury in mice. Proc Natl Acad Sci USA 108:16825-16830. CrossRef Medline

Saruhashi Y, Young W, Perkins R (1996) The recovery of 5-HT immunoreactivity in lumbosacral spinal cord and locomotor function after thoracic hemisection. Exp Neurol 139:203-213. CrossRef Medline

Sato Y, Iketani M, Kurihara Y, Yamaguchi M, Yamashita N, Nakamura F, Arie Y, Kawasaki T, Hirata T, Abe T, Kiyonari H, Strittmatter SM, Goshima Y, Takei K (2011) Cartilage acidic protein-1B (LOTUS), an endogenous Nogo receptor antagonist for axon tract formation. Science 333:769-773. CrossRef Medline

Scheff SW, Rabchevsky AG, Fugaccia I, Main JA, Lumpp JE Jr (2003) Experimental modeling of spinal cord injury: characterization of a force-defined injury device. J Neurotrauma 20:179-193. CrossRef

Schwab ME (2010) Functions of Nogo proteins and their receptors in the nervous system. Nat Rev Neurosci 11:799-811. CrossRef Medline

Silver J, Miller JH (2004) Regeneration beyond the glial scar. Nat Rev Neurosci 5:146-156. CrossRef Medline

Simonen M, Pedersen V, Weinmann O, Schnell L, Buss A, Ledermann B, Christ F, Sansig G, van der Putten H, Schwab ME (2003) Systemic deletion of the myelin-associated outgrowth inhibitor Nogo-A improves regenerative and plastic responses after spinal cord injury. Neuron 38:201-211. Medline

Steward O, Sharp K, Yee KM, Hofstadter M (2008) A re-assessment of the effects of a Nogo-66 receptor antagonist on regenerative growth of axons and locomotor recovery after spinal cord injury in mice. Exp Neurol 209:446-468. CrossRef Medline

Takase H, Kurihara Y, Yokoyama TA, Kawahara N, Takei K (2017) LOTUS overexpression accelerates neuronal plasticity after focal brain ischemia in mice. PLoS One 12:e0184258. CrossRef Medline 
Wang KC, Kim JA, Sivasankaran R, Segal R, He Z (2002a) P75 interacts with the Nogo receptor as a co-receptor for Nogo, MAG and OMgp. Nature 420:74-78. CrossRef Medline

Wang KC, Koprivica V, Kim JA, Sivasankaran R, Guo Y, Neve RL, He Z (2002b) Oligodendrocyte-myelin glycoprotein is a Nogo receptor ligand that inhibits neurite outgrowth. Nature 417:941-944. CrossRef

Wang Q, Gou X, Xiong L, Jin W, Chen S, Hou L, Xu L (2008) Trans-activator of transcription-mediated delivery of NEP1-40 protein into brain has a neuroprotective effect against focal cerebral ischemic injury via inhibition of neuronal apoptosis. Anesthesiology 108:1071-1080. CrossRef
Zhang L, Zheng S, Wu H, Wu Y, Liu S, Fan M, Zhang J (2009) Identification of BLyS (B lymphocyte stimulator), a non-myelinassociated protein, as a functional ligand for Nogo-66 receptor. J Neurosci 29:6348-6352. CrossRef Medline

Zhang Y, Gu X, Yuan X (2007) Phenylalanine activates the mitochondria-mediated apoptosis through the RhoA/Rhoassociated kinase pathway in cortical neurons. Eur $\mathrm{J}$ Neurosci 25:1341-1348. CrossRef Medline

Zheng B, Ho C, Li S, Keirstead H, Steward O, Tessier-Lavigne M (2003) Lack of enhanced spinal regeneration in Nogo-deficient mice. Neuron 38:213-224. Medline 